\title{
De la "paga" a un derecho social: experiencias y puntos de vista de los beneficiarios gitanos sobre la Renta Mínima de Inserción
}

\section{From a reward to a social right: experiences and points of view of Gypsy beneficiaries of the Social Integration Revenue Policy}

\author{
Ariadna AYALA RUBIO \\ Pôle de Recherche et d'Enseignement Supérieur \\ Université Paris-Est (Francia) \\ ariadna.ayalarubio@univ-paris-est.fr
}

Recibido: 20 de mayo de 2013

Aceptado: 14 de marzo de 2013

\begin{abstract}
Resumen
En este artículo se exponen los diferentes puntos de vista de los beneficiarios de Renta Mínima de Inserción (RMI) de etnia gitana de la Comunidad de Madrid, con especial énfasis sobre la relación entre la posición social de los beneficiarios gitanos entrevistados y la presentación de sí que éstos realizan al construirse discursivamente como candidatos "legítimos" a la recepción de dicha prestación. A través de la descripción de algunos casos paradigmáticos de beneficiarios gitanos de RMI se da cuenta de las distintas estrategias utilizadas para argumentar la veracidad de su demanda de ayuda, a la vez que se exponen las tácticas que éstos despliegan para relacionarse con los Servicios Sociales encargados de gestionar la RMI.
\end{abstract}

Palabras clave: Renta Mínima de Inserción, políticas sociales, etnicidad gitana, gitanos, intervención social, derechos sociales.

\begin{abstract}
This article presents the different points of view of gypsy beneficiaries of the Social Integration Revenue Policy of the Region of Madrid, Spain. The discourses of the people interviewed are presented in relation to their relative social standing and the socio-economic features that are most relevant in explaining their narratives. Special emphasis is placed on describing the way in which they present themselves in order to obtain this social income, and on analysing the elements they make reference to in arguing their legitimacy as recipients. Through the description of some paradigmatic experiences, the different strategies employed in their relations with social workers are introduced.
\end{abstract}

Keywords: Social Integration Revenue Policy, social policies, Gypsy ethnicity, Gypsies, social intervention, social rights.

Referencia normalizada: Ayala Rubio, A. (2013) De la "paga" a un derecho social: experiencias y puntos de vista de los beneficiarios gitanos sobre la Renta Mínima de Inserción, en 
Revista de Antropología Social, 22: 103-136

SUMARIO: 1. Introducción. 2. La clasificación de los beneficiarios gitanos de acuerdo a diferentes estratos sociales. 3. RMI, desconfianza y contexto de percepción de los Servicios Sociales. 4. El nerviosismo ante los Servicios Sociales: la auto-representación de los beneficiarios gitanos de peor posición social como sujetos sin poder de negociación. 5. Entre la "necesidad" y la ciudadanía: experiencias y estrategias de auto-presentación.6. Conclusión. 7. Referencias bibliográficas.

\section{Introducción}

En este artículo se exploran los distintos puntos de vista de los beneficiarios de etnia gitana de la Renta Mínima de Inserción (RMI) y se exponen algunos casos paradigmáticos de las distintas maneras en que éstos se relacionan con los profesionales de la red de intervención social que gestiona y aplica esta política social en la Comunidad de Madrid. Asimismo, se presentan los elementos analíticos que dan sentido tanto a la relación de los gitanos beneficiarios de RMI con los Servicios Sociales como al tipo de demanda de ayuda que efectúan y, asimismo, a los argumentos que más frecuentemente esgrimen para ello.

A partir del trabajo de campo etnográfico y de entrevistas en profundidad a beneficiarios gitanos de la Renta Mínima de Inserción de la Comunidad de Madrid ${ }^{1}$ se presentan sus discursos sobre esta política social y la manera en que se dibujan como sujetos que ameritan la percepción de ayudas sociales destinadas a colectivos vulnerables o en situación de exclusión social.

En otros artículos (Ayala, 2009; Ayala y García, 2009b), centrados en la configuración formal de la ley que regula la RMI y en las distintas estrategias profesionales de presentación y aplicación de dicha ley en la Comunidad de Madrid, se ha mostrado que la información sobre los aspectos novedosos y más empoderadores de esta política social, que dotarían de mayor capacidad de negociación y de autonomía a

${ }^{1}$ La autora le agradece al Ministerio de Educación, Cultura y Deporte el apoyo recibido a través de la beca del Programa de Formación del Profesorado Universitario (FPU). Gracias a ella, entre mayo de 2006 y agosto de 2008 se realizó trabajo de campo etnográfico en varios asentamientos chabolistas de la Comunidad de Madrid (Santa Catalina, El Cañaveral, y dos zonas de la Cañada Real Galiana), así como entrevistas en profundidad a 39 personas de etnia gitana beneficiarias de RMI y a 32 profesionales del ámbito de la intervención socio-sanitaria de la Comunidad de Madrid. De igual manera, este artículo se nutre de algunos de los datos que se produjeron para la investigación Actitudes y pautas de comportamiento con relación a la salud de la población gitana madrileña, realizada por Ayala, Jociles, Pérez-Sutil, Villaamil, et al para el Instituto de Salud Pública de la Comunidad de Madrid durante el 2008. Para la citada investigación se llevaron a cabo 8 meses de observación participante en asentamientos chabolistas y en entidades de iniciativa social que impartían cursos de alfabetización a beneficiarios de RMI gitanos, 46 entrevistas semi-estructuradas a 52 personas de etnia gitana de diferentes edades y posición social, 4 grupos de discusión con mujeres gitanas, 3 grupos de discusión con hombres gitanos, 1 grupo de discusión mixto, 3 seguimientos de casos de enfermedad a personas de etnia gitana y 10 entrevistas a profesionales del ámbito socio-sanitario. 
los beneficiarios gitanos de la misma, no se pone a disposición de éstos. También se ha visto que ello está relacionado con el hecho de que la opacidad y falta de transparencia de la información transmitida por algunos profesionales — principalmente los trabajadores sociales de Servicios Sociales - se haya configurado como una estrategia para incrementar su autoridad y, de este modo, de apuntalar su poder sobre los beneficiarios catalogados como conflictivos, faltos de motivación o "cronificados" en los Servicios Sociales, categorías frecuentemente utilizadas para referirse a los beneficiarios gitanos de la RMI.

Por su parte, los gitanos entrevistados que perciben la RMI, son conscientes de la existencia de distintos "estilos profesionales", lo que expresan a través de un léxico que remite al azar y a la suerte para relatar cómo, según el profesional que les "toque", tendrán mayores o menores probabilidades de que la prestación les sea otorgada, así como de poder negociar la no participación en los proyectos de integración asociados al cobro de la prestación económica (la cual toma la forma, frecuentemente, de talleres de aprendizaje de la lecto-escritura gestionados por entidades sin ánimo de lucro). Perciben, por tanto, una gran arbitrariedad en los modos de actuación de los trabajadores sociales de Servicios Sociales, lo cual, unido a la desconfianza incorporada — por la vivencia cotidiana de discriminación y racismo derivada de la pertenencia al colectivo gitano-, produce en ellos, cuando menos, una cierta intranquilidad a la hora de acercarse a los Servicios Sociales.

Los gitanos perceptores de la RMI reconocen la relación asimétrica de poder que tienen con los profesionales y, por lo general, viven la interacción con ellos como "un examen" en el que son juzgados o evaluados. Se entrevé en sus discursos que temen salir de Servicios Sociales habiendo firmado algún papel que pudiera ir en su contra - haber sido "engañados"-, sintiéndose inseguros en esa relación y recelosos de que de ella se desprendan consecuencias negativas para sus intereses y para su bienestar. La inconsistencia de la información que reciben de los distintos profesionales, la obligatoriedad —o, más bien, la ilusión de la obligatoriedad— de la participación en los proyectos de integración que algunos de ellos les transmiten, y la moralización de sus actitudes y de sus maneras de actuar que caracterizan también la actuación de esos mismos profesionales (regañándoles por "no querer trabajar", por ejemplo), alimentan la sensación de incomodidad, el nerviosismo y la desconfianza cuando han de tratar con los Servicios Sociales (Ayala, 2009). En este contexto de intervención, el establecimiento de una negociación más o menos consensuada del Programa Individual de Inserción o $\mathrm{PII}^{2}$ - antiguo contrato de integración- deviene una utopía.

${ }^{2}$ Antiguo contrato de integración, el Programa Individual de Inserción es el documento en el que, de forma consensuada entre los perceptores de la RMI y los trabajadores sociales de Servicios Sociales, se establecen los compromisos que los primeros aceptan asumir de cara a cambiar su situación social. Aunque legalmente la firma del PII es obligatoria, la Consejería de Familia y Asuntos Sociales (2005) insiste en que el no cumplimiento de los compromisos y/o actividades que en él se consignan no será considerado causa directa de extinción de la prestación económica. 


\section{La clasificación de los beneficiarios gitanos de acuerdo a diferentes estra- tos sociales}

El discurso sobre la RMI de los distintos perceptores gitanos entrevistados no se puede comprender sin hacer referencia a la posición social que éstos ocupan. Es por ello que en este artículo se presentan sus discursos de acuerdo a la inclusión de los entrevistados en distintos estratos sociales: bajo, medio-bajo y medio ${ }^{3}$. Esta tipología ha sido establecida atendiendo a la combinación de varios factores que se han considerado relevantes para la aparición de un lugar discursivo desde el que el sujeto puede concebir para sí un proyecto individualizado de ascenso social ${ }^{4}$. Un factor clave que marca la diferencia entre unos estratos sociales y otros, y entre las diferentes visiones de la RMI que expresan los beneficiarios gitanos, responde a la posición en la que se ubican para explicar y dar sentido a sus comportamientos. Y una pregunta que surge a este respecto es: ¿en qué medida explican sus actos haciendo referencia a las costumbres o normas sociales colectivas - mediante frases como "así se ha hecho siempre" o "así lo hacemos los gitanos" —o lo hacen a partir de decisiones individuales tomadas autónomamente en función de unas expectativas coherentes con un proyecto vital, como puede ser la inserción en el mercado laboral formal, el cambio de empleo, el acceso a mayor formación escolar, etc.La aparición de un lugar discursivo para un sujeto-individuo guarda relación con

${ }^{3}$ En otro lugar (Ayala, Jociles, Pérez-Sutil, Villaamil, et al., 2008) se exponen las razones por las que se consideran relevantes las distinciones de la población gitana según esta clasificación en estratos sociales (estrato bajo, medio-bajo y medio), categorías construidas a partir tanto de factores estructurales (ver siguiente nota a pie) como de ciertos discursos y prácticas de las personas de etnia gitana, que se mostraron como relevantes en la investigación ya citada Actitudes y pautas de comportamiento con relación a la salud de la población gitana madrileña. Esta distinción no es estrictamente equivalente a la que habitualmente se usa con la población mayoritaria paya, porque tiene en cuenta variables diferentes como, por ejemplo, el distinto valor que los gitanos de los estratos sociales bajo y medio-bajo otorgan al trabajo asalariado como elemento de reconocimiento social, o la influencia que la relación con las instituciones sociales tiene para quienes, residiendo en poblados chabolistas, se socializan en contacto casi permanente con los distintos profesionales de la intervención social. Esta clasificación de los sujetos gitanos en estratos sociales se ha planteado, entonces y ahora, como una herramienta heurística de carácter flexible. De hecho, a través de ella no se ha pretendido teorizar sobre las clases sociales, sino dar algunas claves de interpretación de diferencias internas dentro del colectivo estudiado, por un lado, para entender por qué se dan una serie de malentendidos en la comunicación entre los investigadores y los sujetos gitanos que suelen compartir una serie de condiciones económicas, urbanísticas, sociales, etc. y, por otro lado, para reducir y ordenar (de una manera coherente, exhaustiva y que conlleve, como se ha indicado, un cierto potencial heurístico) la heterogeneidad de prácticas y discursos en torno a la RMI que presentan los gitanos que han constituido las unidades básicas de análisis de la investigación que ha dado origen a este artículo.

${ }^{4}$ Los factores relevantes tenidos en consideración para el establecimiento de las diferencias entre unos estratos sociales y otros son principalmente: modo de residencia (nomadismo, sedentarización, residencia en chabola temporal o continuada, etc.), lugar de la misma (que incide en la posibilidad de movilidad para acceder a los recursos existentes, en este caso, en la Comunidad Autónoma de Madrid), actividades laborales de los miembros de la familia (mercado formal / mercado informal o naturaleza de esas actividades), formación escolar de los miembros de ésta (escolarización prolongada o no), existencia de un proyecto vital de ascenso social, uso estratégico de las instituciones en favor de ese proyecto y participación en el culto evangélico. 
un proceso de individualización según el cual éste se concibe a sí mismo, al menos en parte, como artífice de su futuro. Ésta es una de las características principales que distingue a los sujetos incluidos en el estrato medio de aquellos pertenecientes a los estratos bajo y medio-bajo, y abre la posibilidad de que los miembros del colectivo gitano elaboren sus demandas de ayudas sociales en términos de ciudadanía, es decir, apelando a su condición de sujetos de derechos a la vez que dibujándose a sí mismos como individuos responsables que están cumpliendo, a la par, con las obligaciones asociadas a los mismos.

Los sujetos comprendidos en el estrato bajo suelen concebir sus trayectorias vitales como una reproducción, de acuerdo a "las normas gitanas", de los modos de vida heredados de sus padres, como es el caso de casarse mediante la boda gitana o de continuar ejerciendo las actividades económicas de la familia ${ }^{5}$. De hecho, tienden a hacer referencia a las "costumbres" o "tradiciones" para explicar sus actos individuales, de manera que estas costumbres y normas son presentadas por ellos, a nivel discursivo, de un modo que hace pensar que ejercen - y, a través de ellas, "lo colectivo"- una fuerte presión sobre los individuos, dificultando así la puesta en práctica de acciones diferentes a las socialmente aceptadas y/o esperadas. En suma, no se abre un lugar para el sujeto individual en el marco de estos discursos, en donde frases como "los gitanos lo hacemos así" se ofrecen a menudo como respuesta a preguntas que, en realidad, están dirigidas a las personas con las que se habla. Personas que también sostienen, por ejemplo, que "no es cosa de gitanos" saber de trámites burocráticos o administrativos como los que permiten obtener la RMI y que no se sienten cómodas en sus contactos con las instituciones públicas o con sus profesionales. Buscan, entonces, relacionarse con ellas sólo para cuestiones muy puntuales, y lo hacen en un contexto de relaciones de subordinación y dependencia.

En cambio, en los discursos de los gitanos beneficiarios de la Renta Mínima de Inserción pertenecientes al estrato medio-bajo, sí hay un lugar para el sujeto individual en lo que concierne a ciertos ámbitos de prácticas y relaciones ${ }^{6}$. Así, expresan,

${ }^{5}$ Haciendo un esfuerzo clasificatorio, y aun a riesgo de simplificar las diferencias internas existentes en cada estrato social, se puede decir que quienes se han considerado integrantes del estrato bajo suelen ser personas con pocos ingresos socio-económicos, con nula o escasa formación escolar y con trabajos — en caso de realizarlos - que tienden a ser desempeñados por los varones y, por lo general, en la economía informal (chatarreo o venta ambulante sin permiso oficial, actividad como temporeros agrícolas, etc.). Es común que residan — aunque este aspecto no sea determinante - en asentamientos chabolistas y que no participen en la Iglesia Evangélica. Las personas pertenecientes a este estrato social que tienen más edad recuerdan haber vivido como nómadas en su juventud y la mayoría de ellas no ha estado escolarizada. No recurren a las instituciones públicas a no ser que sea estrictamente necesario (por ejemplo, en caso de enfermedad grave) y se sienten incómodas, como se verá en este artículo, en su relación con ellas.

${ }^{6}$ Las personas incluidas en el estrato medio-bajo suelen tener unos ingresos económicos y un nivel de escolarización escasos, pero relativamente superiores a los del estrato bajo (así, por ejemplo, algunas han estado escolarizadas y las más jóvenes saben leer y escribir). Tienden a dar valor a la educación y a la inserción en el mercado laboral aunque, por lo general, se encuentran desempleados y desempeñando actividades de venta ambulante o de chatarreo a la vez que cobran la RMI, así como proyectan la formación escolar más bien como una aspiración para sus hijos, algunos de los cuales están cursando, de hecho, la enseñanza secundaria obligatoria. Es 
por ejemplo, que les gustaría formarse y encontrar un empleo en algún momento de sus vidas, lo que pone de manifiesto que elaboran planes individuales orientados hacia un futuro distinto, aunque también - como se verá- muestran signos de que no se sienten preparados para dar comienzo a esos planes, es decir, para emprender los cambios - de rutinas, de conductas, de relaciones sociales, etc.- que su consecución implicaría. Al igual que los entrevistados del estrato bajo, delegan en otros - sobre todo en los profesionales de las instituciones públicas con las que entran en contacto- la gestión de los trámites burocráticos necesarios para relacionarse con ellas y poder acceder a los recursos que ofrecen, si bien tienen mayor conocimiento de las mismas y de la forma de proceder en estos casos. Por ejemplo, piden asesoría profesional para solicitar prestaciones sociales, para conseguir abogados de oficio o para averiguar qué hacer si reciben una carta de desahucio. Por otro lado, fuera de estos ámbitos de actuación, en los que están obligados a relacionarse con las instituciones públicas y sus profesionales, suelen atribuir sus comportamientos individuales a las normas socialmente aceptadas dentro del colectivo gitano.

En suma, es importante destacar que, a medida en que los sujetos van elaborando proyectos de ascenso social, van restringiendo paralelamente la apelación a las "normas colectivas" para explicar sus formas de hacer, sentir y pensar. Hay que tener en cuenta, por otro lado, que lo que se ha denominado "proyecto de ascenso social" no es más que el establecimiento deliberado de un proceso a través del cual los sujetos buscan homologar su forma de vida a la de la sociedad mayoritaria, para lo que van desplegando estrategias que entrañan una mejora de su formación y/o de su desempeño laboral y, de este modo, de sus condiciones de vida. Este proceso de búsqueda consciente de un cambio social, económico, residencial, experiencial, etc. va acompañado de un distanciamiento explícito con respecto a quienes califican de gitanos "cerrados" o "antiguos", que asocian a la falta de "modernidad", a la ignorancia y a la pobreza. Quienes en mayor medida han elaborado ese "proyecto de ascenso social" son los gitanos beneficiarios de la RMI que forman parte del estrato social medio?.

Estos sujetos se conciben a sí mismos como integrados en la sociedad y capaces de establecer relaciones igualitarias con las instituciones públicas. Cuando se refie-

frecuente que residan en viviendas de protección oficial o, si no, en las chabolas o, incluso, en las casas bajas mejor dotadas dentro de los asentamientos chabolistas.

${ }^{7}$ Estos sujetos tienen un nivel económico que, aunque no sea alto, les permite vivir de una manera desahogada cuando complementan sus ingresos con prestaciones como la RMI. A nivel educativo, suelen estar formándose para acceder a un empleo asalariado, por lo que intentan relacionarse con distintas instituciones y organizaciones que pueden ayudarles a conseguir este objetivo. Es común que se dediquen a actividades como el chatarreo o la venta ambulante con permiso, y algunos lo hacen en la economía formal. La mayoría de las personas que se pueden encuadrar en esta clase media, al menos entre las entrevistadas, participan activamente en la Iglesia Evangélica. Residen a menudo en viviendas en altura, ya sean de su propiedad o compartidas con familiares, y tienen conocimientos suficientes sobre las características y el funcionamiento de las instituciones públicas como para relacionarse con ellas siguiendo sus lógicas internas y sintiéndose cómodas en esas relaciones. Son estas personas las que, como veremos, se auto-definen en términos de "normalidad" y emiten sus demandas de ayuda bajo la lógica de ciudadanía, caracterizándose a sí mismos como ciudadanos responsables con derecho a percibir ciertas prestaciones sociales. 
ren a sus formas de hacer, sentir y pensar suelen catalogarlas como "normales" - es decir, se atribuyen a sí mismos "la normalidad"- y se defienden del estereotipo de "el gitano ignorante" que, según dicen, es el que no quiere aprender ni progresar en la vida. Son personas que, por lo general, tienen expectativas de conseguir un empleo a través de una mayor y mejor formación, haciendo un uso estratégico de las instituciones para lograr sus objetivos - ya sea porque conciben los cursos de alfabetización vinculados a la RMI como una posibilidad de mejora laboral o, para poner otro ejemplo, porque utilizan sus alianzas con los trabajadores sociales para recibir subvenciones de diverso tipo-, lo que muestra que se relacionan con ellas y con sus profesionales de una manera más igualitaria que los integrantes de los estratos bajo o medio-bajo. Las instituciones sociales, por tanto, dejan de ser concebidas por los sujetos incluidos en el estrato medio como agentes externos que buscan imponer ciertos modos de pensamiento y acción que se ven como ajenos, para pasar a ser consideradas como aliadas o como colaboradoras estratégicas para la consecución de determinados fines elegidos por la persona. Es decir, las relaciones que establecen con las instituciones son vividas, en estos casos, como respondiendo más a lógicas de reciprocidad que a lógicas de imposición, de suerte que los gitanos beneficiarios de la RMI de clase media enfocan dichas instituciones no tanto en términos de dependencia como de posibilidades. Es preciso aclarar aquí que, dada la manera en que se ha establecido la categorización por clases sociales - ver notas a pie 2, 3, 4 y 5 -, es posible pertenecer al estrato social medio y cobrar la RMI, puesto que el cobro de esta prestación responde a la imposibilidad de insertarse laboralmente en unos términos que no supongan la pérdida económica para la unidad familiar, pero no impide que se tengan otras fuentes de ingresos, por lo que es integrado por las familias gitanas como una de las vertientes de sus estrategias productivas, en particular, de la que se denomina combinación de ingresos, estrategia que es aceptada por todos los entrevistados y que supone la consecución de ingresos combinando aquellos procedentes de la Renta Mínima de Inserción con otros procedentes de actividades realizadas en la economía informal.

\section{RMI, desconfianza y contexto de percepción de los Servicios Sociales}

El discurso sobre la Renta Mínima de Inserción de los perceptores gitanos de los estratos sociales bajo y medio-bajo contiene una visión de la misma que la presenta más como un derecho adquirido históricamente por ser "pobres" y "gitanos", que como una prestación social que se recibe por el cumplimiento de ciertos requisitos formales de acuerdo a la lógica de los derechos de ciudadanía. Estas personas no se refieren a ella con un léxico que haga referencia a los derechos y obligaciones incluidos en la normativa que regula la ley de Renta Mínima de Inserción de la Comunidad de Madrid — Ley 15/2001, de 27 de Diciembre de 2001, y Decreto 147/2002, de 1 de Agosto de 2002, por el que se aprueba el Reglamento de la Renta Mínima de Inserción de la Comunidad de Madrid, publicado en el BOCM de 14 de Agosto de 2002-. Aunque sí utilizan frases como "tengo derecho a la paga" o como "sólo pido lo que me corresponde", estos beneficiarios hablan de la RMI como si se tratase 
de algo que diesen por sentado por haber resistido ciertas situaciones de pobreza y exclusión — circunstancias que, por tanto, han "dado derecho" a ella-, por lo que nunca la mencionan como una prestación económica que conlleva ciertos requisitos que se tienen que cumplir para que sea concedida. Es común, por tanto, que para justificar que les hayan otorgado la RMI, aduzcan el hecho de que algunos de sus familiares y conocidos de etnia gitana también la reciben o la han recibido. El cobro de la RMI es percibido por estos beneficiarios como una obligación de asistencia por parte del Estado, viviéndose como una suerte de "donación" de los poderes públicos ante la prolongada vivencia de situaciones precarias y/o de vulnerabilidad social, como "un regalo o una deuda" de esos poderes hacia él (Dubet y Vérétout, 2001: 41) y, en cierto sentido, como una compensación a las penurias vividas.

Hablar de la RMI supone, en el caso de estos usuarios, hablar de los trabajadores sociales que la gestionan. A parte de esto, no es común que dediquen tiempo a conversar sobre esta política social ni sobre las instituciones que la gestionan, temáticas que no son consideradas relevantes. Por otro lado, la forma en que se refieren a la RMI tiene relación con el momento de sus vidas en que conocieron los Servicios Sociales, así como con las dinámicas que establecieran con ellos. La mayoría de los gitanos beneficiarios de la RMI de los estratos bajo y medio-bajo, al menos de los que han sido entrevistados, no suelen guardar una memoria clara del tiempo en el que empezaron a contactar con esos Servicios Sociales y, en general, han tenido una experiencia prolongada con sus profesionales. Al contrario de lo que sucede con quienes se relacionan con esta institución social por situaciones repentinas de desempleo - con múltiples "entradas" y "salidas"-, estos otros beneficiarios se caracterizan por llevar largos periodos de tiempo en contacto con ella, en ocasiones desde la década de los 90, periodo en el que el trabajo social madrileño tenía un claro cariz asistencialista. Suelen ser, por tanto, sujetos catalogados por los profesionales de la misma bajo la categoría de "usuarios cronificados" o "usuarios acomodados". Se tratará, a continuación, de dar algunas explicaciones que permitan contextualizar la peculiar relación que estos gitanos beneficiarios de la RMI de los estratos bajo y medio-bajo mantienen con los Servicios Sociales.

Dado que, como se ha comentado, cuando son interpelados sobre la RMI y las instituciones que la gestionan, no dedican apenas espacio en sus discursos a tratar el tema - fuera de describir las características de sus trabajadores sociales y cómo consideran que les tratan-, tendría poco sentido intentar analizarlos para inferir algo más que la propia constatación de la poca importancia que le conceden al mismo. Debido a ello, en este artículo se ha optado, en su lugar, por reconstruir la experiencia de algunos casos paradigmáticos de beneficiarios de la RMI de los distintos estratos sociales para dar sentido, por un lado, a esa ausencia en sus discursos de contenidos referidos a la RMI y, por otro, para contextualizar sus narraciones y ciertas tácticas que desarrollan cuando se relacionan con los profesionales del trabajo social. Se pretende, de este modo, reflexionar sobre algunos elementos que permiten comprender la aparición de similitudes, por un lado, en la manera en que los integrantes de cada estrato social se relacionan con los Servicios Sociales y con los profesionales que aplican la RMI y, por otro lado, en las argumentaciones 
que esgrimen cuando entran en contacto con éstos de cara a solicitar ayudas. Las referencias a las teorías de autores como Fassin (2000a, 2003, 2004) y Castel (1996) sirven para enmarcar algunas de las actitudes y comportamientos de estos gitanos beneficiarios de la RMI, en la medida en que arrojan luz sobre las demandas de ayudas sociales que, en general, provienen de personas que están en situación de exclusión. Un aspecto a resaltar que servirá para encuadrar los discursos y experiencias de los entrevistados de los estratos bajo y medio-bajo es que su subjetividad y auto-reconocimiento no dependen de la valoración derivada de la inserción en la economía formal. De este modo, la recepción de ayudas económicas y el extenso contacto con los Servicios Sociales no suponen, para ellos, signo alguno de descenso social o sentimiento de vergüenza. De hecho, los Servicios Sociales y sus profesionales forman parte de su cotidianeidad, de manera que hablar de éstos y de "la paga" - término coloquial mediante el que muchos entrevistados se refieren a la RMI- les lleva a describirlos, a comparar los unos con los otros y a relatar cómo lidian con ellos. Es común que critiquen la fría actitud de los trabajadores sociales, así como el tener que "contar mentiras" para causarles empatía y convertirse en demandantes legítimos de esta prestación económica — en un contexto, además, de reconocida escasez de recursos y de alta competitividad por ellos-: "Estoy cansada de tener que contar cuatro mentiras para que me den una ayuda", decía una gitana beneficiaria de la RMI, de 45 años, durante la entrevista que le realicé.

A pesar de la retórica garantista que cabe encontrar en la regulación de la Renta Mínima de Inserción, los gitanos se refieren a ella en unos términos que dejan ver que recibirla no está libre de contraprestaciones, es decir que saben que, a cambio de la prestación económica, se espera de ellos una contribución a la altura de sus posibilidades. Así, en primer lugar, y dado que el marco en el que se relacionan con los profesionales que gestionan la RMI es de desconfianza y de asimetría de poder, cuando se conversa con ellos sobre esta prestación económica, suelen exponer los distintos argumentos a los que tienen que recurrir para que éstos reconozcan como legítima su petitición de ayuda. Son conscientes, por tanto, de que han de construir un relato creíble ante ellos. El hecho de que los demandantes de ayudas sociales tengan que contar de un modo socialmente reconocido su sufrimiento y su pobreza como condición sine qua non para conseguir el beneplácito de los profesionales ha sido remarcado por autores como Fassin (2004: 258-261), quienes lo han presentado como una de las contradicciones de las políticas públicas actuales, a la vez que como un instrumento de la gobernabilidad contemporánea.

En nuestras sociedades, se espera de los asistidos que, a cambio de los bienes que reciben para sobrevivir, ofrezcan un relato coherente de su penuria. En lo que se refiere, en particular, a los solicitantes de la RMI, han de aportar "el relato sobre su vida, con sus éxitos y sus fracasos" (Castel, 1996: 473) no sólo para justificar lo que demandan, sino para "manifestar su buena voluntad" (Fassin, 2000a: 956). Ello supone demostrar la necesidad de la ayuda que se está demandando a través de un proceso de victimización. Acercarse a Servicios Sociales implica "desnudarse" en el sentido de dar información íntima sobre uno mismo, para justificar niveles de pobreza y/o precariedad que doten de legitimidad a la demanda que se está efectuando 
ante la institución de que se trate. En cierto sentido, supone "feminizarse" en la medida en que hay que mostrar vulnerabilidad y ésta suele asociarse a lo femenino ${ }^{8}$. Por otro lado, estos relatos, si bien distan de ser decisivos en las deliberaciones profesionales, sí se presentan como una pieza clave del dispositivo de la intervención social pues, como asegura Fassin (2004: 248), "la administración se humaniza en esta individualización de los tratamientos", dado que dichos relatos funcionan como "el suplemento de alma de la gestión de las demandas de ayuda" . Ahora bien, como plantea el mismo autor- aquí cabe preguntarse qué necesidad hay de estos alegatos autobiográficos cuando ya se ha entregado la documentación que objetivamente muestra si se tiene derecho o no a las distintas ayudas.

El sujeto en contacto periódico con los Servicios Sociales es interpelado a hacer una presentación de sí mismo que pone de manifiesto que la relación que se urde alrededor de los pobres implica más que intercambios materiales (Fassin, 2000a: 956), dejando patentes los canjes de prestaciones económicas por relatos autobiográficos que testifiquen la veracidad del sufrimiento alegado ${ }^{10}$. En las conversaciones informales que he mantenido tanto con gitanos perceptores de la RMI del estrato social bajo, residentes en asentamientos chabolistas, como con beneficiarios pertenecientes al estrato medio-bajo, ha surgido a menudo el tema de que con los trabajadores sociales "hay que tener cuidado", hay que medir lo que se les dice para evitar que "te quiten la paga". Por su lado, los trabajadores sociales expresan la sensación de que son ellos los que están siendo "engañados" por los gitanos, y que ante la más mínima concesión por su parte, éstos intentarán por todos los medios no responsabilizarse en asumir cambio alguno. Ello no es más que otro ejemplo de la desconfianza desde la cual, como se ha dicho, se relacionan unos con otros. Así, una mediadora social gitana, de 32 años, me contaba durante una conversación que mantuvimos en la ONG donde ésta trabajaba que los propios Servicios Sociales "les obligan a mentir", puesto que si declarasen alguna entrada de dinero "en negro", por ínfima que fuese, les sería negada la prestación económica, dejándoles en una situación familiar muy vulnerable.

La memoria histórica que los miembros del colectivo gitano en posiciones sociales más bajas guardan de la relación con los profesionales de la ayuda social no contribuye a crear un clima de confianza, ya que piensan que "dar" demasiada información a los Servicios Sociales —o a otras instituciones públicas - acaba yendo en su contra, pudiendo ser utilizada por éstas para aumentar la rigidez y/o vigilancia sobre el colectivo. En esta línea, Serrano y Arriba (1998) afirman que la declaración

${ }^{8}$ Idea defendida en el informe inédito "El grado de satisfacción con las figuras profesionales de la intervención social por parte de las familias usuarias de los Servicios Sociales de Puente de Vallecas", demandado por la Empresa de Educadores Sociales y realizado durante el año 2009 con Sergio García García.

${ }^{9}$ Traducción propia.

${ }^{10}$ En la obra recién citada, el autor sostiene que el despliegue de un dispositivo de exposición del sufrimiento puede ser visto como un ejercicio de subjetivación impuesto a los pobres, denominando "política moderna de la piedad" a esta forma de acercarse a la gestión de la miseria (Fassin, 2000b: 974, 981). 
de ingresos en la economía informal fue utilizada, en el periodo de aplicación de la política predecedora, el Ingreso Madrileño de Integración o IMI, como justificación para intensificar el control sobre las familias gitanas, siendo más exigentes en el tipo de documentación que se les pedía para la renovación anual de la prestación. Esto ha sido asumido por los gitanos beneficiarios de la RMI, quienes expresan que los trabajadores sociales "tienen la sartén por el mango", por lo que no pueden controlar plenamente los resultados de la interacción con ellos. En lo que se refiere, en especial, a la entrega de "papeles", sienten que están en desigualdad de condiciones - de saber, y por tanto, de poder- con respecto a los profesionales del trabajo social.

En la Comunidad de Madrid, donde los recursos públicos se están recortando cada vez más en consonancia con "los planes de ajuste que se están produciendo drásticamente en nuestro país" (Zamanillo, 2011: 7), las clases medias y altas están optando por el pago de los servicios sociales y sanitarios. La RMI queda situada como una prestación económica marginal y poco conocida en un contexto socioeconómico donde priman los discursos políticos referidos a "la crisis" de las instituciones públicas y a la necesidad de establecer medidas de co-pago por parte de los ciudadanos. Los llamados "derechos sociales de solidaridad" se alejan, en este contexto, de una concepción garantista, solidaria y universal de los mismos - como prestaciones, por ejemplo, conducentes a evitar la vulnerabilidad social- y van insertándose en el imaginario colectivo como recursos dedicados a paliar las situaciones de extrema necesidad ${ }^{11}$.

Ahora bien, los gitanos aquí incluidos en el estrato medio-bajo y en el estrato medio no responden a la imagen de la exclusión social más severa, por lo que son evaluados con gran detenimiento por los profesionales para determinar si verdaderamente tienen derecho a la RMI, pensada desde esa visión reduccionista de los derechos sociales que se acaba de señalar. Varios de los profesionales entrevistados dicen "estar cansados" de que los gitanos obtengan prestaciones económicas únicamente por el hecho de su pertenencia étnica. Y, comúnmente, la sospecha de que reciben ingresos en la economía informal enturbia constantemente su relación con estos perceptores de la RMI, lo que contribuye a complicar el establecimiento de una relación de confianza (Serrano y Arriba, 1998).

${ }^{11}$ Cabe reseñar, por otro lado, que la legitimidad social de la RMI en el ámbito español es mucho menor que, por ejemplo, en el francés, siendo una desconocida para la ciudadanía española en general. El desconocimiento de la prestación predecesora, el IMI, fue detectado en una de las primeras evaluaciones oficiales que se realizaron de ella (Aguilar, Gaviria y Laparra, 1993). Esto mismo se pone de manifiesto actualmente con respecto a la RMI en el hecho, por ejemplo, de que en distintos foros profesionales se haga precisamente la propuesta de darla más a conocer. Del mismo modo, en varias de las jornadas tituladas "A Favor de la Inclusión Social” que organizaron conjuntamente durante el año 2007 la Fundación Luis Vives y el Ministerio de Trabajo y Asuntos Sociales, los distintos ponentes y algunos participantes hicieron hincapié en la necesidad de dar a conocer esta política social. Sin embargo, muchos de los profesionales entrevistados no están de acuerdo con esta propuesta, dado que, según argumentan, acarrearía un "efecto llamada" que incrementaría en demasía el número de demandas de esta prestación lo que, afirman, atraería a los sujetos que, sin necesitarla verdaderamente, la solicitarían "para ver si cuela". 
De hecho, ser beneficiario o demandante gitano de la RMI es suficiente para levantar sospechas, que llevan a los profesionales a indagar sobre la naturaleza de la demanda por considerar que los gitanos han mejorado bastante sus condiciones de vida, por lo que tal vez no tengan derecho a cobrar la prestación económica ${ }^{12}$. San Román (2010, [1997]: 277) sostiene que los gitanos ya no responden únicamente a situaciones de grave marginación social y que "poco a poco ha ido creciendo un segmento social gitano acomodado", pudiéndose decir que han dejado de ser los candidatos prototípicos para la recepción de ayudas sociales. Los profesionales consideran que la RMI hace un flaco favor a los gitanos, actuando como un freno al desarrollo de sus capacidades, habida cuenta que es considerada una política social que produce dependencia y los sitúa en una situación de "precariedad — que también cabe calificar de - acomodada", esto es, lo suficientemente estable como para que no tengan que esforzarse por cambiarla puesto que ello perjudicaría a nivel económico al conjunto de la unidad familiar.

"La paga" se presenta en los discursos de los gitanos de estrato bajo y mediobajo como un subsidio de carácter vitalicio, un cuasi-derecho adquirido por haber vivido excluidos y marginados por la sociedad, lo que tiene que ver, a su vez, con su histórica relación con los Servicios Sociales - siempre mediada por dádivas- y entronca con las estrategias productivas desplegadas por la fracción del colectivo más vulnerable socialmente, tendentes a generar recursos combinando distintas actividades — entre ellas, las de la economía informal-.

\section{El nerviosismo ante los Servicios Sociales: la auto-representación de los beneficiarios gitanos de peor posición social como sujetos sin poder de negociación}

La relación con los Servicios Sociales y el tipo de demanda de ayuda que realizan los solicitantes/beneficiarios de la RMI — apelando, en unos casos, al sufrimiento o a la "necesidad" y, en otros, a su condición de "ciudadanos" que cumplen con procedimientos formales asociados a la RMI, guarda relación con variables como la posición social de los mismos, la edad, el género, el nivel educativo, el nivel socio-económico, el número de hijos que tienen, la ocupación laboral, el grado de conocimiento de los Servicios Sociales (medido sobre todo a través del tiempo de contacto con ellos), la participación o no en redes socio-familiares de apoyo - donde se transmite información valiosa - y la existencia o no de un proyecto individual de ascenso social a medio o largo plazo. O, dicho con otras palabras, las formas de pedir ayuda y de relacionarse con los profesionales de la intervención social para llevar a cabo esa petición varían sobre todo en función de las variables recién enumeradas.

${ }^{12}$ Los gitanos perceptores de la RMI, por su parte, confirman en cierta medida las sospechas profesionales al expresar abiertamente que no tienen necesidad de trabajar "al estilo de los payos", quienes se empeñan en "partirse los cuernos" en el precarizado mercado laboral formal. Se vanaglorian, en cierta forma, de la "precariedad estable" que han conseguido al combinar las actividades de la economía informal con la recepción de ciertas ayudas sociales como la RMI. 
De este modo, las personas en situación de exclusión social severa, preocupadas por su subsistencia diaria y que todavía no han recibido la RMI, se relacionan con las instituciones sociales de las que depende su concesión de una manera poco coherente, principalmente en lo que se refiere a la presentación de sí que llevan a cabo ante los distintos profesionales. No suelen elaborar discursos auto-biográficos inteligibles, centrándose — como se verá- en narrar algunas experiencias personales trágicas que piensan que servirán para generar compasión en ellos. Estas personas no dan muestras de conocer cómo desenvolverse con estos profesionales, por lo que sus relatos ofrecen retazos dramáticos de momentos vitales que se exponen de forma inconexa. En cambio, los beneficiarios de la RMI incluidos en los estratos medio-bajo y medio, con más nivel educativo y, generalmente, con una red social de apoyo que cuenta con experiencia acumulada en el trato con los Servicios Sociales, son capaces de articular sus relatos auto-biográficos en términos legibles para las instituciones y de cumplir el papel que se espera de ellos.

Se puede decir, así, que tanto los solicitantes/beneficiarios del estrato medio-bajo como los del estrato medio son conscientes, aunque no lo expresen abiertamente, de la necesidad de realizar una "presentación de sí" (Fassin, 2004) que produzca una reacción favorable en los trabajadores sociales que gestionan la RMI y que evalúan periódicamente sus progresos. La diferencia estriba en el grado de seguridad y confianza que unos y otros muestran a la hora establecer sus demandas en unos términos legítimos para la institución y en la manera en que se conciben como sujetos con poder de negociación ante los Servicios Sociales. Lo que algunos autores denominan la cultura del asistido incluye la disposición a producir un cierto tipo de narraciones, es decir, a presentarse a sí mismos de un determinado modo, que los solicitantes de ayudas sociales incorporan a partir de experiencias en este ámbito. A través de los relatos auto-biográficos, los sujetos buscan reconocimiento social ante las instituciones públicas, pero sólo quienes tienen un cierto capital social y han establecido un contacto prolongado con ellas producen relatos coherentes, legibles para los profesionales de las mismas.

Los solicitantes/beneficiarios del estrato social bajo no conocen bien el funcionamiento de la RMI ni saben cómo comportarse con los profesionales, por lo que quedan a merced de lo que unos y otros les dicen que tienen que hacer. Así, manifiestan e, incluso somatizan, indicios de sentirse como barcos a la deriva cuando se dan cuenta de que no entienden cómo funcionan las instituciones con las que tienen que relacionarse ni dominan los distintos protocolos que rigen en ellas: no distinguen la RMI de otras prestaciones sociales; todo lo que tenga que ver con la Administración Pública les provoca malestar e inseguridad; frente a la documentación oficial se paralizan; buscan el consejo de cualquier persona paya ${ }^{13}$ que tengan cerca; piden que se les traduzca lo que pone en los impresos más sencillos; cuando consiguen lo que precisan, se quejan de tener que realizar tantas gestiones; y a veces solicitan que se les escriba en un papel la información que deben aportar para que, en casa, los hijos que saben leer se encarguen de dársela.

${ }^{13}$ Calificativo usado por las personas de etnia gitana para referise a los no gitanos. 
Éste es el caso de Julia, una mujer de 45 años, perceptora de la RMI y madre de cinco hijos, que en el momento de la entrevista residía en el asentamiento El Cañaveral $^{14}$. Julia tiene varios hijos absentistas: un adolescente de 14 años y una niña de 5 años que, aunque está escolarizada, no suele asistir a la escuela infantil. Su rutina consiste en estar con su hija pequeña en el poblado mientras hace quehaceres domésticos; una rutina que rompe una vez al mes cuando se acerca al barrio de Vicálvaro a cobrar la RMI y aprovecha para hacer "la compra grande". Su marido, Rafael, de 50 años, se dedica a la chatarra, aunque durante varios meses ha estado sentado en la puerta de casa por una avería en su furgoneta. De apariencia joven pero con la mitad de los dientes caídos, aduce no arreglarse la dentadura porque "eso no es cosa de gitanos", precisando que él puede sobrevivir perfectamente a base de "nolotiles". Cuando se le pregunta por qué no hace algo por arreglarse la dentadura se ríe y dice que "eso no es cosa de gitanos" y que puede sobrevivir perfectamente a base de "nolotiles". En una de las visitas al poblado, Julia se acercó a mí, con cara de preocupación, y me pidió que le leyera una carta que le había llegado "del abogado". La carta exponía que su marido tenía que aportar cierta información de cara a un juicio que se iba a celebrar con relación a una tierra que tenía en herencia en Extremadura. Tras leerle la carta, Julia relajó su expresión de angustia y Rafael exclamó: “¡Ah!, sí, lo de la tierra de Cáceres. ¡Menos mal que estás aquí, que si no habría roto la carta directamente!". Mientras les comentaba a dónde tenían que llevar la documentación, Julia no cesaba de suspirar, hablaba entre dientes, se quejaba de la mala suerte que tenían y maldecía el hecho de tener que desplazarse por este tema. Entre tanto llegó una mujer de unos 65 años vestida de luto, a la que antes había visto en la zona más pobre del poblado — con chabolas construidas de lona y palés de madera-, donde vivían familias gitanas de origen portugués. La anciana, Victoria, después de saludar a Julia y Rafael, me pidió que me acercara a su casa a leerle una carta. Cuando llegamos, un hombre de unos 25 años me explicó, con acento portugués, que les había llegado de la cárcel donde estaba el hijo de Victoria. El joven resumió la situación con una frase lapidaria: "Le pillaron robando rollos de cobre en una obra y va a estar unos meses encerrado". Ella me entregó la carta y me pidió que le dijera cuál era el horario de visitas y dónde estaba la cárcel a la que habían llevado a su hijo, así como que le apuntara en un papel el primer día y la hora a la que podía ir a verle, comen-

${ }^{14}$ Este asentamiento, originariamente concebido como un barrio de tipología especial (barrios de viviendas prefabricadas construidas fuera de los entornos urbanos para un colectivo específico), se encontraba en la carretera de Vicálvaro a Rivas, a 10-15 minutos en coche particular desde el barrio de Vicálvaro. Comenzó con 80 familias en 1988, que residían en casas bajas prefabricadas y compartían espacios de uso común como una guardería, unos lavaderos y los establos. Según datos del informe realizado por EDIS S.A. para la Consejería de Sanidad y Consumo (2005), en El Cañaveral habitaban 214 familias durante el año 2005, la mitad de las cuales lo hacían en casas de tipología especial, mientras que la otra mitad vivía en chabolas. Este poblado comenzó a ser desalojado por IRIS (mediante convenio con el Ayuntamiento de Madrid) en noviembre de 2008 . 
tándole después al joven que no sabía cómo iba a hacer para pagar el transporte y llevarle algo de comida a su hijo ${ }^{15}$.

El anterior no es más que un ejemplo de que la vida de los gitanos del estrato social bajo está centrada, por lo general, en las actividades de supervivencia diaria y en solucionar los múltiples problemas - familiares, judiciales, económicos...- que les surgen a raíz del desempeño de actividades en la economía informal —multas por falta de documentación en los vehículos o por venta ilegal, encarcelamientos por robos y trapicheos, etc.- . Por otro lado, no manejan suficiente información sobre el funcionamiento de las diferentes instituciones ni tienen capacidad lectoescritora para comprender documentos oficiales o, a menudo, texto escrito alguno, por lo que no saben desenvolverse cuando tienen que gestionar este tipo de documentación o de trámites. En cambio, los gitanos solicitantes/beneficiarios de la RMI pertenencientes al estrato medio-bajo, si bien se auto-representan en las entrevistas y en las conversaciones informales como sujetos "que no saben nada", cuentan con mayor grado de conocimiento acerca de las obligaciones derivadas del cobro de la prestación económica y sobre los procedimientos burocráticos que tienen que enfrentar cuando se relacionan con las instituciones públicas. Del mismo modo, a pesar de que dicen sentirse sin capacidad de negociación cuando se reúnen con sus trabajadores sociales, disponen de una red social y familiar que les permite acceder a información clave para solucionar sus dudas como, por ejemplo, la relativa a los profesionales que pueden asesorarles. A continuación, se exponen algunos casos que ejemplifican cómo los gitanos beneficiarios de la RMI del estrato medio-bajo, aunque no lo reconozcan abiertamente, son capaces, a efectos prácticos, de negociar algunos aspectos de sus Programas Individuales de Inserción (PII) con los profesionales de Servicios Sociales.

Cuando le pregunté a Alma, mujer gitana de 21 años, de origen extremeño y pertenenciente al estrato social medio-bajo, residente en una vivienda ocupada en el barrio madrileño de Colonia Jardín, si sabía que el Programa Individual de Inserción que había firmado podía ser negociado - hay que decir que ni siquiera sabía cómo se llamaba el documento que había firmado-, respondió exclamando: "¡sabía que Raúl — su trabajador social - me estaba engañando!”. Esta reacción espontánea es significativa del marco desde el que Alma interpreta las acciones de su trabajador social, al que - por otro lado - define como "simpático, cariñoso y amable". Hay que tener en cuenta que Raúl, de 35 años de edad, es contrario a forzar a la población a la que atiende a que lleve a cabo actividades de inserción. Por ello, únicamente le ha pedido a Alma que pase cada tres meses por su despacho de Servicios Sociales: "para ir viendo cómo le va". En suma, incluso habiendo dado con un trabajador social que le pide muy poco y al que dice tener estima, Alma siente que ha sido "engañada" por él por no haberla informado de que tenía la opción de no firmar el Programa Individual de Inserción si no estaba de acuerdo con lo que allí ponía. Con todo, no le preguntó en su momento nada acerca de lo que estaba firmando

${ }^{15}$ Reconstrucción basada en las observaciones hechas en el asentamiento de El Cañaveral en marzo de 2008. 
porque, según asegura, estaba nerviosa y no quería poner en riesgo la concesión de la prestación económica, razón por la que ni siquiera se le ocurrió cuestionar lo que allí ocurría. Sostiene, por tanto, que "hubiera firmado cualquier cosa con tal de que le dieran la RMI".

Las distintas experiencias que ha tenido esta perceptora de RMI gitana con profesionales del trabajo social, y su percepción de que éstos actúan según diferentes estilos profesionales, la han llevado a creer que la RMI le será "dada" si el trabajador social "quiere". Así, Alma reconoce que su trabajador social no le ha puesto objeciones para ayudarle a conseguir la RMI, aspecto por el que dice estar agradecida ${ }^{16}$. Para ella, la concesión de la RMI guarda relación con la suerte y con las características personales de su trabajador social, no con el cumplimiento de los requisitos oficiales que regula la ley RMI ni con el objetivo gubernamental de luchar contra la exclusión social. De la siguiente frase de Alma podemos deducir que no se concibe a sí misma como persona con poder a la hora de demandar esta prestación: "A mí me ha tocado todo fatal, fatal. ¡Menos mal que me han dado el IMI por Raúl!, que si no, no lo tengo". (Entrevista a Alma, gitana perceptora de la RMI de 21 años, madre de un hijo, residente de casa ocupada en barrio de zona oeste de Madrid.

La referencia a "los nervios" como reacción al contacto con las instituciones públicas, que aparece en los discursos de algunos solicitantes/beneficiarios de la RMI de los estratos medio-bajo y bajo cuando entran en contacto con sus trabajadores sociales, también se encuentra en entrevistados que nos narran lo que sienten cuando visitan los servicios sanitarios. De hecho, en situaciones en que he acompañado a algunas mujeres gitanas a consultas médicas, estos "nervios" se han corporeizado en forma de estatismo y de retraimiento que les ha obstaculizado la comunicación con los profesionales que las estaban atendiendo, mostrándose —además- cabizbajas, silenciosas y sumisas. Ello me lleva a pensar que, incluso en el caso de que los profesionales - ya sean sanitarios o del ámbito de la intervención social— se esforzasen por informarles de los males que padecen o de las novedades de la RMI, es difícil que en ese estado de "nervios" lograsen captar la información. Los "nervios" responden a una cierta incomodidad y a una cierta inhabilidad para expresarse adecuadamente en situaciones que experimentan como asimétricas, sobre todo en aquellas en que se está evaluando la veracidad de su discurso por parte de profesionales cuyo dictamen puede tener serias consecuencias en sus vidas o en que están hablando con ellos sobre cuestiones acerca de las cuales sienten que "no saben". En cualquier caso, se trata de una incomodidad y una inhabilidad que vivencian no en todo tiempo y lugar, sino de manera muy localizada y sólo ante determinadas personas que representan una autoridad, como sucede en las oficinas de Servicios Sociales y de otras instituciones públicas. Por ejemplo, Alma no actúa en el despacho de Raúl como teniendo poder para negociar. Así, como se ha visto, firma

${ }^{16}$ Fijémonos en que el agradecimiento no es porque se le haya concedido la RMI, sino hacia una persona concreta (aquí su trabajador social) que la ha ayudado a conseguirla poniendo de su parte más de lo que es esperable en estos casos. Ésta es la diferencia entre "el agradecimiento" que siente Alma y el que suelen expresar los solicitantes/beneficiarios de la RMI del estrato social bajo. 
dócilmente los papeles que él le rellena y se va a su casa sin entender bien lo que ha ocurrido. En cambio, la sensación de incomodidad y el nerviosismo de Alma desaparecen cuando está en su casa, incluso en las ocasiones en que está presente su trabajador social, como he podido comprobar cuando he acompañado a éste en alguna de las visitas a domicilio que le ha hecho. En estas ocasiones se ha sentido dueña del espacio, ha dominado la interacción y ha hablado - tranquila, risueña y vivaracha - sobre su vida y sus circunstancias, a la vez que nos ha preparado un café y nos ha ofrecido unos bollos.

A medida que las personas de etnia gitana se relacionan con las instituciones públicas o con personas que las conocen - lo que es más frecuente, como se ha dicho, en los del estrato medio-, los discursos sobre la RMI incluyen nuevos argumentos, se vuelven más elaborados y el nerviosismo en el contacto con los profesionales disminuye, pues aumenta el saber acerca de lo que se espera de ellos y acerca de cómo se va a desarrollar la interacción. Tanto es así que podría decirse que la sensación de nerviosismo es, en buena parte, inherente a la experiencia de los gitanos de los estratos bajo y medio-bajo. Y podría decirse también que los solicitantes/beneficiarios de la RMI que cuentan con una relación prolongada con los Servicios Sociales y otras instituciones públicas han adquirido un cierto capital social que, a medida que ascienden en posición social, contribuye a dotarles de tranquilidad y confianza cuando se relacionan con ellas.

\section{Entre la "necesidad" y la ciudadanía: experiencias y estrategias de auto-presentación}

En este apartado, se tratarán de reconstruir las circunstancias vitales en que tienen lugar las experiencias de los solicitantes/beneficiarios de la RMI, así como de dotar de sentido a las demandas de ayudas sociales que realizan; y se hará a partir de ciertas teorías ofrecidas por algunos autores que han abordado la temática de la exclusión social y la descripción de casos de beneficiarios y/o solicitantes de la RMI que se sitúan en distintas posiciones sociales. Se verá que la manera en que estos sujetos expresan y viven sus demandas varía en función de dichas circunstancias. Así, cuando se está en una situación de "precariedad estable", es decir, cuando se está en posesión de una vivienda de protección oficial y se dispone de algunos recursos económicos ${ }^{17}$, los gitanos que solicitan la RMI acuden a un discurso cuyos argumentos se centran en demostrar la existencia de una "necesidad". En cambio, los usuarios incluidos en el estrato bajo, que suelen encontrarse en situación de pobreza extrema, elaboran discursos sobre su vida que resultan inconexos y son, como se ha dicho, difícilmente legibles por los profesionales.

Se ha destacado anteriormente que los solicitantes/beneficiarios de los estratos medio y medio-bajo están habituados al trato con los profesionales y es frecuente

${ }^{17} \mathrm{La}$ "normalización" que han experimentado los gitanos que, desde hace décadas, cobran la RMI (antes el IMI), junto con la concesión que les han hecho de viviendas de protección oficial (por las que pagan un alquiler módico, que oscila entre los 60 y los 200 euros al mes), ha posicionado a estos beneficiarios de la RMI en una situación de relativo desahogo a la que se denomina aquí de "precariedad estable". 
que hayan participado en proyectos de integración durante bastantes años, por lo que cuentan con expectativas ajustadas sobre lo que pueden esperar de los Servicios Sociales. En cambio, las expectativas que tienen los solicitantes/beneficiarios que no cuentan con una vivienda adecuada ni con dinero suficiente para alimentar a sus familias suelen ser desmesuradas, ya que esperan de ellos una solución mágica - efectiva y rápida - para todos sus problemas. Una consecuencia de su desconocimiento de las funciones y de los modos de funcionar de las distintas instituciones sociales es que, con frecuencia, narran sus circunstancias personales más dramáticas para tratar de entablar una relación cercana con sus interlocutores, pero lo hacen de un modo tan crudo y deshilvanado que - como se viene apuntando- no responden al tipo de narraciones que esas instituciones esperan y están preparadas para comprender.

El caso de Sonia, gitana portuguesa casada con un gitano español drogodependiente, pone de manifiesto que, cuando no se cuenta con capital social que llegue hasta las instituciones sociales, y se ocupa una posición social baja — sin formación, sin habilidades lecto-escritoras, sin red social de apoyo-, el contacto con ellas produce frustración cuando se percibe que no proveen de las ayudas que se les solicita. Además, este caso nos sirve para ver, en el plano de lo concreto, la dificultad que tienen los solicitantes/beneficiarios de la RMI en peor situación social para elaborar un relato sobre su situación vital que sea coherente e inteligible para los profesionales. Sonia no recibe ayuda social alguna, aunque está realizando los trámites oportunos para poder solicitar la RMI. Vive con sus cinco hijos y su marido en una casa ocupada - a la que ha entrado "de patada" - en el distrito madrileño de Vallecas, subsistiendo gracias a donaciones de comida de sus vecinas y al poco dinero que él consigue pidiendo en la calle y chatarreando. La apariencia física de éste está muy deteriorada por el consumo de drogas, y la casa en la que viven se encuentra medio derruida, no tiene servicios y está sucia y con humedades por todos lados. Su marido y ella dejaron la chabola que se habían construido en Cañada Real por estar situada en una zona donde hay venta y consumo de drogas, y ella tomó la decisión de irse de allí porque quería residir en un lugar que no fuera tan peligroso para sus hijos.

Cuando habla de su relación son los Servicios Sociales, Sonia lo hace desde la frustración que siente ante la falta de ayudas que recibe de éstos y las múltiples veces que ha tenido que contar su historia a los diversos profesionales "para nada". Ante su caso, la burocracia de los Servicios Sociales se muestra inefectiva, lenta, excesivamente compartimentada y protocolizada. Sonia, que necesita ayuda para la subsistencia básica - alimentación y ropa para sus hijos, una vivienda apropiada, etc.- - está desesperada ante los protocolos que tiene que seguir para poder cobrar la RMI. Su situación muestra los vacíos y huecos de las políticas sociales de cara a la inclusión social, que no pueden hacer nada para mejorar sus circunstancias vitales - en este caso, además, porque su tarjeta de residencia se está tramitando por haberla perdido en un incendio-. A su vez, deja en evidencia el sinsentido de las 
nuevas normativas de acceso a la vivienda pública para colectivos en situación de necesidad - poco conocidas por los propios trabajadores sociales - que impiden que las personas que están ocupando una vivienda — sea por el motivo que seatengan derecho a solicitar una de protección oficia ${ }^{18}$. Sonia no sólo está preocupada por su supervivencia económica, sino que tiene una orden de desahucio pendiente y dice estar intranquila por la posibilidad de que la Comunidad de Madrid le retire la custodia de sus hijos en caso de "dejarla en la calle".

S: Ahora me tiene que llegar la orden del juez para echarnos. Tengo tres hijos ahora en el cole y estos dos hijos. No sé qué vamos a hacer. Como los del IVIMA son... tal. ¿Para qué tienen los pisos: para los que los necesitan o para los que no? No he echado papeles porque dicen que al estar aquí, de patada, no puedo echar papeles, que tengo que estar empadronada, que al ser de patada no puedo. El día 17 ya me van a hacer lo de la RMI. ¡Es que me la tienen que dar!Pero, la verdad, aquí sólo vienen (los profesionales), apuntan, me dicen cuatro tonterías y se van. Yo llevo aquí un año. Las niñas llevan siete meses en el colegio. ¿No era ya para que las dejen comer en el colegio (con beca)? Porque cuando quieren, lo hacen. Tengo a Estrella (trabajadora social) y aún no he hablado con ella. La que viene y anota es Patricia (educadora). Aquí sólo viene ella. Y nada más.

A: ¿Cuál es la ayuda que necesitarías?

S: Lo que yo necesito más es la vivienda. Aunque no tenga para comer, pero que mis hijos tengan un techo. Porque me van a echar a la calle, y después van a decir que quieren que los niños vayan limpios y duchados al colegio. ¡Cómo los voy a duchar!, ¿en la calle? Aquí hay agua, pero cuando me echen, les tendré que llevar al cole porque, si no, me echan a mí una multa. Pero después echan pegas de que están en malas condiciones. ¡Pero si no te dan un sitio para estar en condiciones! ¡Los pisos del IVIMA son para quienes losnecesitan! Pero ya te he dicho que no me dejan pedirlos.

A: ¿Entonces, quitarías a Patricia (educadora social)?

S: Yo qué se, ¡en lo que más necesito no me ayudan!

A: ¿Y con los niños qué hace (la educadora)?

S: Nada. A mi marido le iba ayudar a meterse en el CAD (Centro de Atención a los Drogodependientes) porque está enganchado, pero él no quiere. Y con nosotros, nada. Ahora vivimos de pedir en el súper, y mi marido se pone por ahí, a pedir en algún semáforo. Muy mal, con tantos niños. Es que no me dan ayuda de ningún tipo. En la parroquia dicen que no tienen comida, que no tienen ropa. Hoy he ido y me he vuelto como he ido. (No te dicen:) "Toma esta ropa, esta leche". Nada, no me han dado nada.

${ }^{18}$ En entrevista telefónica con una persona encargada en el IVIMA de trabajar con gitanos, se confirmó que había introducido el Decreto 74/2009 de 30 de julio como medida para "desincentivar" que los gitanos ocupen viviendas. De este modo, se deja sin protección a personas verdaderamente necesitadas, como es el caso recién descrito de Sonia, cerrando las pocas vías que tiene para poder conseguir una vivienda pública. 
(Entrevista a Sonia, gitana portuguesa, madre de cinco hijos, residente en casa ocupada en barrio de Vallecas.)

Sonia se siente una persona sin poder, a expensas de decisiones que llegan de afuera. Su discurso se muestra incoherente, produciendo un relato auto-biográfico fragmentado, sin hilo conductor, que expresa su deriva vital y su desconocimiento de cómo funcionan las instituciones públicas. Así, trata de contar su historia, pero se detiene en algún acontecimiento concreto como, por ejemplo, la dificultad para lograr alimentos para sus hijos. Acto seguido, mira a los ojos de su interlocutor para pedirle el favor de que la ayude, preguntándole si no conoce a alguien que se apiade de ella y que le pueda agilizar los trámites burocráticos que tiene pendientes. A continuación, protesta de lo injustas que son las instituciones públicas por no ayudarla, por no "darle vivienda" a pesar de no tener dónde meter a sus hijos. Su relato no adquiere sensación de totalidad, sino de hechos contados fragmentariamente para acercarse a la persona que le pregunta por ellos. Ofrece la imagen de una demandante de ayudas sociales de estrato bajo, sin capital social que pueda hacer valer ante los profesionales de las instituciones públicas, sin poder frente a éstas y sumamente desprotegida y frustrada por la situación en la que vive. Busca desesperadamente establecer alianzas personales con cualquiera que conozca, tratando de producir compasión a través de su miseria y demostrando no saber quién, de todas las personas que pasan a verla, tiene capacidad para echarle una mano. En ocasiones, habla como si no se creyese su propio relato, como si tarareara las distintas situaciones de miseria que ha vivido desde la distancia, como si se tratase de una melodía que toca para los visitantes. La asiduidad con la que narra su situación personal ha derivado hacia lo que algunos autores denominan "banalización del sufrimiento social"(Dejours, 1998; Fassin, 2004: 258), que permite entender por qué ciertos solicitantes/beneficiarios de la RMI del estrato bajo comentan, sin ser preguntados y como si no fuera con ellos, sus múltiples penurias familiares.

Los verbos que Sonia utiliza para demandar ayudas — "me tienen que dar", "jes injusto si no me dan nada!"-, denotan una posición desempoderada, estar a la espera de que alguien le haga el favor de gestionarle el acceso a los recursos sociales. Confía en que, entre las visitas de unos y otros, alguien la ayude. En este aspecto, su discurso se muestra también incoherente, dando bandazos desde la defensa de unas opiniones al apoyo de las contrarias. De este modo, cuestiona a todas las instituciones públicas - "no sirven para nada"- y dice que no la apoyan en absoluto, para cinco minutos después afirmar que, en el fondo, sí que le sirve de ayuda el hecho de que una educadora social subcontratada por la Junta Municipal del distrito donde vive se pase de vez en cuando a verla.

A: ¿Alguna cosa que, de los otros servicios o las ayudas, cambiarías?

S: No sé. Es que no sé las ayudas que hay. Los cheques de los niños de los pañales no me los dan porque me han dicho que los han quitado. Nada más, no sé. A mí lo que me duele es que no te den una vivienda. Hay a gitanos a los que, si no les dan vivienda, les dan dinero. Por lo menos que tenga lo básico para los niños. ¡A 
mí no me va a quitar los niños la Comunidad de Madrid! Luego me dirán que no puedo estar en la calle con ellos, ipero si son ellos los que me dejan en la calle!

A: ¿Los trabajadores sociales sirven para algo?

S: Sí, porque si no es una cosa, es en otra en la que te pueden ayudar.

(Entrevista a Sonia, gitana portuguesa, madre de cinco hijos, residente en casa ocupada en barrio de Vallecas).

En suma, Sonia, que no se relaciona con los Servicios Sociales desde hace tiempo, no da signos de saber configurar un discurso sobre su situación adaptado a lo que éstos esperan. Denota, así, no haber acumulado un saber suficiente sobre cómo funciona esta institución y sobre los comportamientos adecuados para solicitar algo en ella.

Si pasamos ahora a considerar a los solicitantes/beneficiarios de la RMI del estrato medio-bajo, encontramos que éstos no actúan ni hablan de un modo que permita inferir que son conscientes de que han de cumplir lo que algunos autores han llamado "las normas de buena conducta de los beneficiarios del Estado Social" (Fassin, 2000a: 956), sin embargo, algunas de sus actitudes y prácticas sirven como evidencia de que han acumulado mayor grado de conocimiento sobre los Servicios Sociales y sobre la importancia de comportarse adecuadamente - es decir, siguiendo ciertas "normas de conducta"- en las relaciones con los profesionales a fin de producir una imagen o impresión en ellos que vaya a su favor. Confrontados con éstos, los solicitantes/ beneficiarios del estrato medio-bajo adaptan su discurso a lo que piensan que se espera de ellos. Dado que como se viene de afirmar, no explicitan en sus discursos conocer las categorías y normas que manejan los profesionales, resulta difícil discernir si la forma que toman sus demandas de ayuda responde al azar o al despliegue de ciertos "desvíos tácticos" (Fassin, 2000a: 956) para lograr encajar dentro de las categorías que piensan que los profesionales utilizan para considerarles acreedores legítimos de las distintas prestaciones.

Es el caso del discurso autoinferiorizante ${ }^{19}$ que varias entrevistadas, situadas en este estrato social, utilizan para hablar de sí mismas, principalmente cuando se les pregunta sobre cuestiones relativas a la gestión de la RMI y otros trámites administrativos que han de llevar a cabo en instituciones públicas. Se ha señalado con anterioridad que declaran estar nerviosas cuando se reúnen con los profesionales y que adoptan posturas subordinadas, que se reflejan incluso corporalmente, cuando

${ }^{19}$ A través de entrevistas y conversaciones mantenidas con residentes en poblados chabolistas y con otros que llevan poco tiempo viviendo fuera de ellos, se puede comprobar que estos gitanos del estrato social bajo, cuando son interpelados a partir de temas que no tienen sentido en su día a día, tienden a calificarse a sí mismos de "dejados" ("los gitanos somos unos dejados") para expresar que no atienden a dichos temas a pesar de ser prioritarios para sujetos con autoridad, como es el caso de los profesionales. Estas expresiones generalizadoras, que acaban reduciendo ciertas conductas a la pertenencia étnica y/o cultural de las personas, llevan a cabo una esencialización o "culturización" de los miembros del colectivo gitano a partir de ciertas prenociones estigmatizantes. Ser gitano pasa, por tanto, por no hacer cosas como ir al médico, "comer bien", etc. (Ayala y Pérez-Sutil, 2007; Ayala Rubio, Jociles, Pérez-Sutil, Villaamil y otros, 2008). 
se relacionan con ellos. Si a estos comportamientos añadimos algunos comentarios y peticiones que a menudo les hacen — como, por ejemplo, "es que yo no sé hacer eso" o "léeme esto y relléname el papel"-, se podría llegar a la conclusión de que estas mujeres son realmente torpes en todo lo que implica demandar ayudas sociales y realizar los trámites pertinentes. Sin embargo, — como se ha indicado para el caso de Alma - el cambio de forma de hablar y de actuar es notorio cuando están en otras situaciones o en otros espacios en los que se sienten cómodas, donde se expresan sin dificultad dejando ver que son mujeres con capacidad de autonomía y decisión en otros ámbitos de sus vidas. Es por ello por lo que argumentamos que la autoinferiorización es, en cierto sentido, una táctica desplegada sobre todo por sujetos de los estratos sociales medio-bajo y bajo que permite no entrar en conflicto con los profesionales, si bien es común que a ojos de éstos no sea una actuación convincente o creíble. Se trata de una forma de hablar y actuar que se puede considerar como una táctica, y no tanto como una estrategia, siguiendo la distinción de De Certeau (1996), puesto que estos solicitantes/beneficiarios de la RMI no suelen desarrollarlas consciente ni deliberadamente como una forma de optimizar sus encuentros con los profesionales ${ }^{20}$. No obstante, se detecta una diferencia destacable en el despliegue de esta táctica en sujetos del estrato medio-bajo y en sujetos del estrato bajo, dado que mientras que, entre los primeros, todo indica que el discurso autoinferiorizante no se acompaña de prácticas que lo confirmen —es decir que la autoatribución de "torpeza" o de "no saber", por ejemplo, no responde a lo que esos sujetos muestran saber hacer cuando actúan en el ámbito de que se trate, a pesar de lo cual nada indica que sean conscientes de esta incongruencia-, entre los segundos, ocurre lo contrario, esto es, que su discurso autoinferiozante suele corresponderse con prácticas que lo corroboran.

Paseo por el poblado chabolista y una chica de unos 20 años sale a mi encuentro y me pide que le lea una carta que le ha llegado de la Comunidad de Madrid. Le digo que le recuerdan que le han dado una subvención para montar un negocio. Se acerca un chico que parece de la misma edad, y me dice: "Nosotros somos muy buenos, hacemos todo lo que Elena y Pedro (trabajadores sociales de IRIS que trabajan en el poblado) nos dicen".

(Registro de campo: observación en asentamiento chabolista Santa Catalina, zona sureste de Madrid, junio 2006)

El caso de Sara, que se describe a continuación, sirve igualmente para ilustrar que algunos beneficiarios, cuando hablan con los profesionales, se presentan a sí

${ }^{20}$ De Certeau identifica las "tácticas" como un tipo de resistencia propio de los sujetos y de los colectivos que se encuentran en una situación de especial vulnerabilidad y las "estrategias" como aquellas otras que se orientan a cuestionar expresamente un determinado status quo, por lo que no se pueden desplegar en esas situaciones, tal como sostiene Jociles (2011) en su estudio sobre las resistencias que interponen —en su caso- las mujeres solas que están en proceso de adopción internacional ante ciertos planteamientos y demandas sostenidos por los profesionales que intervienen en dicho proceso. 
mismos como personas desempoderadas, sin capacidad de actuación sobre sus propias vidas. Sara, una perceptora de la RMI de 23 años del estrato medio-bajo, reside en una casa baja de Cañada Real, es madre de una hija de un año y está casada con un primo suyo. Afirma que está muy descontenta con su vida y que alguien "tiene que ayudarla a conseguir piso de protección oficial". Cuando le hice la entrevista, me relató diversas calamidades personales con un tono psicologicista — resaltando los nervios, las angustias personales, la depresión-, a través de las cuales expresaba la desazón con la que experimentaba sus circunstancias vitales. Si le preguntaba por su relación con los Servicios Sociales o con la institución sanitaria, solía entreverar sus respuestas con múltiples "yo no sé" y hacer referencia a los "nervios" que le entraban cuando tenía que lidiar con sus profesionales. Sin embargo, cuando tuve la oportunidad de observar a Sara en el desarrollo del proyecto de integración en el que participaba desde hacía varios años, o relacionándose con otras mujeres gitanas, se mostraba feliz y cómoda en contacto con las trabajadoras de la ONG que implementaba dicho proyecto, hasta el punto de decir que su profesora de alfabetización era una de sus mejores amigas. Se podría decir, a modo de hipótesis, que la autoinferización de Sara se desplegaba sobre todo cuando se enfrentaba a profesionales de quienes no sabía cómo iban a reaccionar o qué tipo de autoridad podían tener para apoyarla a conseguir la ayuda que solicitaba, en este caso, una vivienda de protección oficial, y a través de ella se ajustaba, de un modo casi automático a alguna de las categorías - como la de mujer soltera o la de mujer depresiva, por ejemplo- en las que dichos profesionales suelen encajar a quienes consideran "pobres legítimos" o "buenos pobres"

Gitanas como Alma, pertenecientes al estrato medio-bajo, no recurren como estandarte a la narración de situaciones de penuria o sufrimiento extremo —que, por otro lado, no podrían demostrar-, sino que apelan a "la necesidad" económica como eje-guía de sus relatos de demanda de ayuda. Alma produce un discurso ordenado sobre su vida, parándose en los hechos que dan sentido a su demanda de escasez de recursos. Explica claramente los hechos relacionados con su descenso de poder adquisitivo, poniendo ejemplos como el haberse visto obligada a cambiar de

${ }^{21}$ Que alguien diga que "está necesitado" de cara a conseguir ayudas sociales implica tratar de ser encajado dentro de la categoría de "buen pobre"; categoría que apunta a quien ni se aprovecha ni miente, a la vez que testimonia estar en una situación verdaderamente delicada. Siendo conscientes de esto, una estrategia discursiva común en las personas gitanas entrevistadas es la de distanciarse de los "gitanos aprovechados", de esos otros que no son "buenos pobres". Así, Alma critica a los gitanos que se benefician de múltiples recursos sociales, a quienes acusa de acumular, además de "chabolas buenas", casas de protección oficial, trabajo en la economía formal, etc.: "Pues, no, los que tienen dinero no se pueden aprovechar de eso, porque hay otras personas que lo necesitan de verdad, como yo, y no tengo derecho. Porque a ver, ¿dónde me voy yo?, ¿a una chabola? Es que no hay ya, si no ¿tú te crees que si hubiera una chabola no me iba yo? Y saber que de aquí a 2-3 años tengo derecho a un piso (si estuviera en chabola)... Pero claro, hay otros con dinero, con mafia, que tienen las obras, van a la chatarra, van a trabajar. Después de que están montados les dan el IMI y luego les dan el piso. ¡A eso no hay derecho!”. (Entrevista a Alma, gitana perceptora de la RMI de 21 años, madre de un hijo, residente de casa ocupada en barrio de zona oeste de Madrid). 
marca de pañales - ya no usa Dodots - para su hijo o el haber tenido que dejar de comprar en Carrefour. Alma, a diferencia de Sonia, utiliza expresiones relativas a la planificación temporal de su vida diaria, lo que pone de manifiesto que no vive en una situación de incertidumbre. Donde Alma tiene dificultades es en la planificación de su vida en el mediano y el largo plazo puesto que, como se ha dicho ya en otro lugar, tiene que buscar vivienda por haber recibido una orden de desahucio.

La RMI son 380 euros, que hoy en día te los gastas en nada. En comida se me va. Con el niño, en petisuís, en pañales, en toallitas.... El niño antes usaba Dodots, pero tuve que cambiar a los pañales baratos. La ropa me la dan a veces mis vecinas. Me adapto a lo que venga, pero a lo primero se pasa muy mal, hasta que planificas: dónde gasto este dinero, dónde este otro. Mi día a día lo vivo. Yo no sé si hoy me voy a ganar 20, 30 euros (vendiendo).

(Entrevista a Alma, gitana perceptora de la RMI de 21 años, madre de un hijo, residente de casa ocupada en barrio de zona oeste de Madrid.)

A pesar de que dice estar sola y no tener apoyos, recibe dinero de su ex-compañero e información de una prima que vive en Madrid. A su vez, se relaciona con algunas vecinas y ha recurrido a un hermano de su madre, que también reside en Madrid, para que le ayudara a buscar una chabola. Por tanto, si bien asegura que no tiene a nadie, cuenta — a nivel práctico - con suficiente red social como para conseguir información valiosa y solucionar asuntos acuciantes. Un ejemplo de esto surgió cuando recibió la orden de desahucio, pues a raíz de recibirla, Alma se movilizó yendo a Servicios Sociales y pidiéndole ayuda a su ex-compañero, quien la llevó en su furgoneta a los distintos lugares donde tuvo que presentar documentación para que le fuese asignado un abogado de oficio. Esto es, contó con ayuda para realizar todas las gestiones pertinentes. Por otro lado, Alma no expresa los sentimientos de frustración que produce una posición vital de extrema necesidad, como la que ocupa Sonia, y sabe de la existencia de las "normas de buena conducta", mencionadas más arriba, que se esperan en la relación con los Servicios Sociales. Tiene miedo de que sus propios actos la traicionen, de no saber producir un relato que sirva para legitimar una demanda de ayuda a los ojos de su trabajador social. Sin embargo, es una mujer guapa, joven, muy vital... y sabe expresarse bien tanto oralmente como por escrito. A diferencia de Sonia, a quien se ve ajada y poco arreglada, ella se ocupa de su apariencia física, de manera que el cuidado corporal y estético es otro elemento que las distingue. Y si bien Alma dice que no se siente con capacidad para negociar nada con su trabajador social, ha logrado convencerlo de que su Programa Individual de Inserción no incluya la asistencia a ningún "cursillo" ni comenzar de manera inmediata un proceso de búsqueda activa de empleo. Su auto-calificación como "gitana ignorante" es, en cierto sentido, una coartada que le sirve para relacionarse de forma más eficaz con determinados profesionales. Se podría decir incluso que busca esconderse detrás de la palabra "ignorante" para evitar las presiones para la inserción social que teme recibir de los trabajadores sociales. Su experiencia con alguno de los que ha tratado previamente la han puesto sobre aviso de "las reglas del juego" 
y, a partir de ella, ha armado su discurso de un modo que le permite defenderse de esas presiones. Así, aunque los "nervios" no dejan de aquejarla cuando se relaciona con las instituciones públicas, en general, y con los Servicios Sociales, en particular, en la práctica se desenvuelve bastante bien en esa relación y ha logrado no asistir a ningún curso de formación ni comprometerse a la búsqueda de empleo. Ella sabe que, para algunos profesionales, querer cuidar a su hijo es una razón suficiente para no participar en "cursillos", por lo que ésta es la que aduce ante Raúl. De igual modo, estos profesionales asumen el que las mujeres se encarguen de los cuidados de la familia como una parte de la "cultura gitana", por lo que ven plausible que no confien en las escuelas infantiles para hacerse cargo de sus hijos cuando son menores de tres años. En consecuencia, Alma le dice a Raúl que cuando su hijo tenga tres años y deba ir a "la guardería", se planteará buscar empleo. Por tanto, cabe concluir que la adaptación de esta beneficiaria de la RMI a las categorías que utilizan los Servicios Sociales indica que posee las competencias sociales necesarias para realizar sus demandas en los términos que espera dicha institución (Messu, 1991). En suma, Alma demuestra tener más conocimientos que Sonia sobre qué puede y no puede negociar en sus relaciones con los Servicios Sociales, y lo demuestra en la práctica puesto que, en la entrevista que se le hizo para esta investigación, expresó no tener ninguna habilidad ni saber para ello.

A: Cuando me vine aquí, desde que me vi sola, fui a donde Raúl y le pedí ayuda.

E: Me has dicho que fue por tu prima que pediste la RMI. Si no te hubiera contado tu prima que existía esa ayuda, ¿no tendrías ni idea?

A: Nada, ni idea. Ella fue la que me dijo que había una ayuda. Nosotros la llamamos el IMI. Me dijo: "Mira, hay un IMI que te dan 500 euros, y con eso puedes tirar perfectamente el mes”. Y digo:“¡Ah, pues, sí!” Pero como estaba antes (viviendo) allí con la suegra, pues, allí no la pedía porquele tenía a él (al padre de su hijo) y tampoco me hacía falta el dinero. A ver si me entiendes. Para comer, de sobra tenía. Estaba bien. Pero desde que me vine aquí, a esta casa, necesitas comida, necesitas ropa, muchas cosas, ¿sabes? Y desde que me vi tan necesitada, pues, a mi prima, que se llama Telma, le pregunté. Y le dije: “¿Tú no tienes ninguna ayuda?". "Sí, pues, los Servicios Sociales te dan una ayuda, que se llama el IMI, que te dan casi 500 euros al mes, que puedes tirar perfectamente". Y fui donde José (su primer trabajador social). Una persona malísima, muy... A ver si me entiendes. Nada más ir a pedirle información, me dice: "Pues, trabaja", dándome como esquinazo, como que no quería ayudarme. Y yo digo: "Pues, como me toque éste, yo no consigo nada". Y luego me tocó una muchacha que se llama María, muy buena la muchacha. Me dio un papel con la dirección donde tenía que ir, me puso direcciones, me ayudó. Y luego me pasaron a Raúl, y desde entonces ya no me han vuelto a cambiar, ni quiero que me cambien, y ya está.

E: Yo me acuerdo que Raúl me dijo que él trató de explicarte que te venía bien ir a cursillos. ¿Tú ya sabías que eso te lo iban a decir?

A: Sí, sí.

E: ¿Te lo dijo tu prima? 
A: Sí, porque ella va dos veces a la semana a los cursos, pero cuando los niños tienen tres años, cuando van al cole, tienes que ir a un curso.

(Entrevista a Alma, gitana perceptora de la RMI de 21 años, madre de un hijo, residente de casa ocupada en barrio de zona oeste de Madrid.)

Por otro lado, aunque reconoce que no quiere trabajar, Alma elabora un discurso que ensalza las bondades de la inserción laboral haciendo referencia, sobre todo, a la "independencia" que le daría el poder ganar dinero en el futuro.

A: La primera persona que quiere trabajar soy yo, porque ganas más dinero, eres independiente pero, claro, mi hijo está antes que nadie.

E: ¿Pero si te ofrecieran un trabajo de 700 euros al mes lo cogerías?

A: Lo cogería.

E: ¿Lo cogerías aunque te quiten el IMI?

A: Pues sí, pero cuando mi niño tenga tres años. Pues, sí. Según qué trabajo, qué hora, para que pudiera trabajar y estar con mi hijo. Yo a mi hijo no lo dejaría doce horas (en la escuela infantil). (Refiriéndose a la entrevistadora:) Ya verás cuando tengas tú el tuyo. Si estuvieras sola, no lo dejarías ni por nada del mundo. ¡Un hijo es un hijo!

(Entrevista a Alma, gitana perceptora de la RMI de 21 años, madre de un hijo, residente de casa ocupada en barrio de zona oeste de Madrid.)

Sin embargo, Alma - como otras perceptoras de la RMI entrevistadas incluidas en el estrato medio-bajo - no muestra signos, sino todo lo contrario, de creerse verdaderamente ese discurso. Así, me llamó la atención que, cuando le pedí que me relatara cómo fue el encuentro con su trabajador social en el que le solicitó la RMI, cambiara de acento y pasara a adoptar uno que sonaba a "más gitano". El deje que utilizó evocaba el utilizado por las vendedoras gitanas en los mercadillos para convencer a los transeúntes de que les compren algo de mercancía. En cierto sentido, el acento gitano que ha aprendido en contacto con actividades como la venta lo usa para persuadir también a los profesionales que reparten ayudas sociales. Es una incorporación sutil, que se ha observado realizando acompañamientos con distintos gitanos perceptores de la RMI y/o solicitantes de ayudas sociales: una vez no se necesita convencer o persuadir, el acento cambia — sonando a menos "gitano"- y la "necesidad" se deja de aducir a modo de cantinela.

En suma, Sonia, Sara y Alma se presentan a sí mismas como merecedoras de las prestaciones y/o ayudas sociales que solicitan, pero lo hacen desplegando discursos de victimización diferentes. Sonia lo hace con retazos vitales, Sara catalogándose como depresiva y Alma adoptando un lenguaje proclive a mostrar la aceptación de los valores que piensa que tiene su trabajador social, esto es, afirmando ante él que sí quiere trabajar, aunque no en este momento.

A medida que se asciende en posición social y formación, los gitanos solicitantes/beneficiarios de la RMI del estrato medio incorporan a sus discursos la lógica de 
los derechos de ciudadanía y realizan afirmaciones sobre la importancia de asumir procesos de autonomización y responsabilización personal. Comienzan a hablar de ellos mismos como sujetos emprendedores y deseosos de cambio vital, y de los trabajadores sociales en clave profesional. Los solicitantes/beneficiarios de posiciones sociales más bajas establecen principalmente la distinción entre unos y otros trabajadores sociales en base a su actitud con respecto a la concesión de la prestación. Así, les catalogan, por un lado, de trabajadores sociales "buenos" o "simpáticos" si los perciben dispuestos a "darles" las ayudas que piden sin oponer obstáculos, o de "malos" o "antipáticos" si les ponen trabas o les reciben "de mala gana". En cuanto a los de estrato medio, también consideran "buenos" a los trabajadores sociales que les facilitan la realización de las gestiones necesarias para conseguir las ayudas pero, en este caso, consideran que ello forma parte de su labor profesional, por lo que los ven como merecedores de "agradecimiento" sólo cuando se implican en ella más de lo que es exigible que lo hagan.

Felisa y Javier, matrimonio gitano de estrato medio, de 34 y 36 años, respectivamente, son un buen ejemplo de cómo el ascenso social conlleva la adopción del lenguaje de "los derechos de ciudadanía". Padres de seis hijos, Javier se dedica a la venta ambulante y Felisa, que es la titular de la RMI dentro de la unidad familiar, asiste regularmente a distintos cursos de formación en entidades de iniciativa social. Aunque ya se encuentren involucrados en un proceso de ascenso social a través de la formación y/o de la búsqueda planificada de vínculos con las instituciones públicas y sus profesionales, también dicen que no buscan la inserción laboral, porque, —en su caso - a pesar de desear hacerlo, ello bajaría su nivel de vida debido a la pérdida que les supondría dejar de cobrar la RMI. Este matrimonio no maneja una concepción de la RMI como pensión vitalicia e incluye en su relación con los Servicios Sociales un discurso que dota de valor a la responsabilidad individual. Para ellos, lo que otorga legitimidad a su demanda de ayuda es, en sus palabras, "la verdad" que acompaña a todas sus peticiones, además del conocimiento de sus derechos y obligaciones. Ello les sitúa en una posición más simétrica con respecto a los trabajadores sociales que la de los entrevistados de clases sociales más bajas. Tanto Javier como Felisa se sienten, por tanto, con poder ante la institución a pesar de reconocer que siempre queda un resquicio de miedo o de "nervios" cuando se reúnen con su trabajador social. Aun así, y a diferencia de Alma y Sonia, dan detalles sobre las funciones que diferencian a unos y otros profesionales y relatan sentirse cómodos en contacto con las distintas instituciones.

A: ¿Alguna vez habéis ido a Servicios Sociales y os habéis puesto nerviosos?

J Yo soy más nervioso que Felisa, en el sentido de que reivindico una cosa que me veo con derecho y me veo con tanto derecho que a lo mejor la pierdes (la razón) por las formas.

F: Yo me desenvuelvo muy bien pero siempre me gusta tirar de Cristina (educadora social subcontratada por la Junta Municipal).

J A veces pierdes los papeles porque dices: " $i Q u e$ verdaderamente me hacen falta (los recursos que solicitan)!". Soy una de las personas que tienen que tomar un poco de conciencia y ser más humanitarios, y hay casos que te enfadas y dices: 
“Óscar (trabajador social de Servicios Sociales), esto creo que es así, de esta manera, y a usted le pagan para que haga esta gestión, y nada más exijo que la realice. No te exijo nada más que realices la gestión y des unos informes verídicos a los de arriba, que para eso te pagan. Y no me vayas a venir con la historia de que te falta un papel y me quitéis los 500 euros que es de lo que vivo". Entonces, fue una ocasión que sí que reivindiqué un poquito.

(Entrevista a Javier — 36 años, ocupado en la venta ambulante - y a Felisa -34 años, beneficiara de la RMI-, 6 hijos)

El verse como sujetos conocedores de sus derechos les otorga seguridad a la hora de transmitir su demanda de ayuda, aspecto éste que no aparece, como se ha visto, en los solicitantes/beneficiarios de la RMI de menor posición social. Cuando se relacionan con los profesionales exigen un servicio "profesional", por lo que ya no delegan en otros las distintas gestiones como un acto dependencia, sino que buscan obtener un servicio público de calidad. De este modo, se puede afirmar que el hecho de que los solicitantes/beneficiarios conozcan cómo funcionan las instituciones públicas y los procedimientos para solicitar las ayudas cambia la actitud con la que se acercan a ellas. Por otro lado, Javier y Felisa muestran, a través de su discurso, que han establecido relaciones de alianza y de amistad con diversos profesionales, en quienes se apoyan en caso de necesitar consejo con respecto a cualquier trámite o procedimiento burocrático. De este modo, otros elementos que les distinguen de los perceptores de la RMI de inferior posición social son, por una parte, que han incluido a los profesionales, en términos de una cierta igualdad, dentro de su red social y, por otra parte, que cuentan con información que les dota de cierta capacidad de maniobra y reivindicación de sus derechos.

A: ¿Y te funcionó reivindicar?

J: Pues, sí, de hecho, como vas con la verdad, pues, tienes acceso a todos lados. $\mathrm{Y}$ vio mi verdad y me ayudó. Y estoy agradecido. Pero ya tuve que reivindicar porque, a lo mejor, se cree que no sabes un poquito de tus derechos, ¿eh?

F: Pero eso pasa en todos lados, que por ser gitanos se piensan que somos ignorantes.

J: Estoy agradecido porque desde esa vez tomó su opinión y sacó su conclusión y me solucionó el problema.

F: Podemos ser más ignorantes pero no tontos.

(Entrevista a Javier — 36 años, ocupado en la venta ambulante - y a Felisa -34 años, beneficiara de la RMI-, 6 hijos)

Este matrimonio, por tanto, habla del derecho a la RMI relacionándolo con otros derechos sociales, como el de la vivienda o el más amplio de la protección social. A diferencia de otros beneficiarios de la RMI, son capaces de salirse de su situación personal para mostrar que tienen una idea del funcionamiento general de los derechos de protección social existentes en la Comunidad de Madrid y en el Estado. Este aspecto no aparece en los perceptores de los estratos bajo y medio-bajo, quienes - como se ha visto - hacen referencia principalmente a su situación de penuria y 
a la información recibida de familiares y conocidos a través del "boca a boca", de manera que se presentan a sí mismos como sujetos "a la deriva" e inermes ante las decisiones de los profesionales aunque, como se indicó, en el caso de beneficiarias como Alma esta pose discursiva es la táctica que le posibilita escapar de las presiones profesionales hacia la inserción porque, en la práctica, esta beneficiaria ha logrado negociar ciertos aspectos con relación a su Programa Individual de Inserción. En cambio, Felisa y Javier saben qué pueden esperar de las instituciones públicas, lo que posibilita que sus relaciones con $-\mathrm{y}$ lo que consigan de - ellas no quede a la merced de los diferentes estilos profesionales. En su discurso, a diferencia de Alma, Sonia y Sara, se describen como sujetos con poder. Exigen ser atendidos adecuadamente como ciudadanos con derecho a la RMI. Felisa, por su parte, se está formando voluntariamente en informática, después de haber participado durante tres años en un programa orientado a mujeres, en el que concurrían inmigrantes, gitanas y payas, que se desarrollaba en el centro de Servicios Sociales de su distrito y era llevado a cabo por educadoras sociales que habían sido subcontratadas por la Junta Municipal. Está inmersa en un proceso de ascenso social que se refleja tanto en sus prácticas como en su lenguaje; así, por ejemplo, se inscribe voluntariamente en nuevos cursos cuando considera que ya ha cumplido ciertos objetivos formativo-laborales que se había propuesto o, para poner otro ejemplo, se refiere a su tiempo de formación como "ocio", no como "trabajo". Además, Felisa y Javier aseguran que se sienten orgullos de fomentar que sus hijos estudien la secundaria, si bien confiesan que no están logrando que asistan regularmente al IES en que están matriculados.

Si nos fijamos en otro aspecto de los discursos de Javier y Felisa, podremos apreciar que han asumido como propios ciertos valores de clase media desde los que otorgan sentido a sus vidas. Felisa, por ejemplo, cuando contaba en la entrevista que estaba haciendo averiguaciones para sacarse el graduado escolar en una escuela para adultos, lo argumentaba diciendo que quería ir a los cursos "para distraerse un poco" y "pasárselo bien", poniendo de manifiesto — como se ha indicado- que concibe la formación como parte de su tiempo de ocio. En este sentido, mientras que las mujeres gitanas incluidas en los estratos bajo y medio-bajo no suelen hablar en términos que permitan identificarlas más allá de su papel de madres y cuidadoras, Felisa y otras perceptoras de la RMI del estrato medio que también han sido entrevistadas se presentan a sí mismas a partir de una idea de gitana moderna, que ha hecho suyos el deseo de cambio, la valoración positiva del aprendizaje y el disponer de tiempo para el disfrute personal ${ }^{22}$. En comparación con Sonia y con Alma, Felisa se autodefine como alguien con motivaciones de ascenso social, y lo hace en términos de sujeto individual, aspecto definitorio de las personas incluidas dentro de lo que se ha considerado estrato medio gitano. Finalmente, no hay que olvidar que los discursos de estos perceptores de la RMI han sido conformados, sobre todo,

${ }^{22}$ Imagen ésta abonada desde distintos cursos de formación organizados conjuntamente por instituciones públicas y organizaciones no gubernamentales que trabajan con población gitana beneficiaria de la RMI. 
a través de un contacto cotidiano con las profesionales que gestionan la RMI y/o que trabajan impartiendo formación en proyectos de integración, lo que les hace ser conscientes del valor que éstos conceden a la constitución de un proyecto de cambio personal conducente a la inserción laboral y a una determinada forma de concebir y experimentar el tiempo y la propia vida. Los discursos de estos sujetos, por tanto, no pueden de ser leídos fuera de esa relación con la intervención profesional.

Otro caso de gitana beneficiaria de la RMI que voy a comentar aquí es el de Rosario, mujer de 30 años, con dos hijos, que se desenvuelve de manera muy competente en los cursos de la RMI - al menos en los en los que he realizado observación participante- . Se trata de un caso que deja ver tendencias diferentes al recién expuesto de Felisa a pesar de compartir con ésta algunos de los valores del estrato medio que se han reseñado, si bien no todos — como se verá-. Es una mujer que no duda en afirmar que quiere que su hija se eduque todo lo que pueda, a la vez que sostiene que ella quiere trabajar "fuera de casa". Vive en un piso de protección oficial por el que paga menos de cien euros al mes y acude dos días a la semana a clases de alfabetización en su barrio — zona suroeste de Madrid-, asistiendo también algunas semanas a las actividades complementarias que convoca la misma entidad que organiza esas clases. Rosario es el prototipo de mujer gitana del estrato mediobajo que vive en una situación de precariedad estable. Esta beneficiaria de la RMI ha asumido, en contacto prolongado con los Servicios Sociales y las entidades de iniciativa social, la inserción laboral como parte central de los discursos que elabora sobre su propio futuro aunque, en la práctica, revela signos de no estar preparada para emprenderla. Así, por ejemplo, cuando a Rosario le surgió la oportunidad de desempeñar un trabajo como limpiadora, que ella manifestaba frecuentemente que quería realizar como complemento a la RMI, dio múltiples excusas que pospusieron indefinidamente la fecha de su incorporación al mismo de manera que acabó por no hacerlo nunca. Lo que busco con la exposición de este incidente no es destacar que Rosario "mintiera" sobre su deseo de trabajar - tal como algunos profesionales tienden a interpretar cuando se enfrentan a incidentes similares, tal como se ha visto en otro apartado-, sino poner de manifiesto que lo que, a nivel discursivo, se expresa como algo deseable - como un sueño, un deseo o una aspiración - a menudo no resulta o lo más factible o lo más conveniente a nivel práctico, puesto que Rosario, por ejemplo, aunque no disfrute de una situación económica boyante, tiene ingresos suficientes para cubrir sus necesidades básicas, que no serían compensados por el salario que recibiera trabajando en el sector de la limpieza, máxime cuando ello le supondría, además, tener que abandonar una vida que está organizada alrededor de los cursos de la RMI y de sus actividades domésticas — compra, cocina, cuidado de hijos, etc.- - Por otro lado, los cambios a este respecto se materializan cuando las mujeres han interiorizado previamente un proyecto de vida que incorpora un amplio abanico de valores de clase media - es decir, no sólo el de inserción laboral sino también el de autonomía personal o el de "independencia" a través del trabajo asalariado, para enumerar únicamente dos más-y ello se ha acompañado con la aparición de la idea de "sujeto individual" con tiempo para sí mismo, que aleja a la mujer del rol de cuidadora y de la responsabilidad no-compartida de las labores 
domésticas. Rosario no se ve capaz de salir de su ámbito de acción, el del barrio, de lo que ya sabe hacer y constituye su rutina diaria, a pesar de que hable de ello como si se tratase de uno de sus anhelos y sepa que es lo legitimado por las profesionales con las que se relaciona y hacia las cuales siente un gran afecto. En resumen, no puede cambiar lo suficiente como para culminar lo que, tal vez un tanto a la ligera, dice desear.

Es común que, en el marco de interacción con los profesionales, mujeres como Alma o Rosario se atrevan a "soñar en voz alta". Así, expresan deseos, expectativas futuras, motivaciones sobre sí mismas que muestran que están visualizando, al menos utópicamente, un cambio de vida. Ello podría ser considerado en sí mismo como una de las consecuencias "positivas" de los proyectos de alfabetización o, en general, de formación en los que estas mujeres gitanas se integran a través de la RMI, dado que ellas, debido a las frecuentes interpelaciones de las educadoras acerca de su potencial para cambiar, para realizar cosas diferentes a las que ya realizan, se sienten invitadas a soñar, a verse a sí mismas emprendiendo procesos de cambio personal que tal vez puedan culminar con la inserción laboral. Por tanto, declaraciones acerca de "querer cambiar", como la que hacía Rosario en el incidente expuesto más arriba, hay que tomarlas más bien como quimeras, como utopías o como ensoñaciones sobre la propia capacidad de transformarse; quimeras, utopías o ensoñaciones que se generan y se despliegan en un contexto donde es muy valorado el deseo de dar forma a un proyecto de cambio personal. Cabría incluso decir que estas quimeras, utopías o ensoñaciones se han constituido a través de un "diálogo interétnico realizado en términos argumentativos y democráticos" entre los profesionales y los beneficiarios de la RMI, para expresarlo con palabras de Cardoso de Oliveira (1993: 27). Este "diálogo persuasivo" 23 de los profesionales - y, en especial, de las educadoras y profesoras que imparten los cursos de los que se ha hablado- es el marco social en que se han ido construyendo los sueños y los deseos de cambio de estas mujeres gitanas que, a nivel práctico, no se pueden materializar porque no son coherentes ni con su experiencia ni con sus posibilidades prácticas, socio-culturales y/o económicas.

\section{Conclusión}

En todo caso, todos los gitanos solicitantes/beneficiarios de la RMI expresan sentirse "juzgados" en su contacto con los Servicios Sociales. De hecho, la relación con éstos está mediatizada por la concepción que manejan de los trabajadores sociales como agentes con algún tipo de influencia en la concesión/retirada de la prestación económica. De este modo, dichos solicitantes/beneficiarios de la RMI desarrollan, delante de esos trabajadores sociales —y otros profesionales del ámbito de las políticas sociales-, formas de presentarse a sí mismos como merecedores legítimos de

${ }^{23}$ Cardoso de Oliveira (1993: 27) distingue entre el diálogo persuasivo, mediante el que se trata de convencer a través del ejercicio de la argumentación a los interlocutores, y el no-diálogo, mediante el que no se establece ningún tipo de comunidad de comunicación y se centra en imponer autoritariamente ciertos valores y hábitos a "los otros". 
la RMI que varían dependiendo, principalmente, —como se ha visto- del mayor o menor capital social y del mayor o menor capital cultural que tienen en su haber.

La escasez de recursos ha convertido la demanda de ayudas sociales en una especie de mercado moral, donde las personas deben "venderse" como el solicitante/ beneficiario más perfecto, más honorable, más sincero — el que dice "la verdad"o más miserable —el que "más sufre"-. En este contexto socio-ideológico, demostrar que se hace todo lo posible para mejorar, que se hace con empeño y esfuerzo y que no se es "un parásito del Estado", ha pasado a formar parte del acerbo cultural de los perceptores de RMI del estrato medio. Así, cuando "el discurso del sufrimiento" no convence a los profesionales, los gitanos se describen a sí mismos mediante "el discurso de la normalidad", con el que tratan de presentarse como ciudadanos dignos de recibir las ayudas sociales.

Se puede decir, así, que la auto-victimización de los solicitantes/beneficiarios de RMI y la auto-denominación según las categorías que piensan legítimas para las instituciones públicas son, en cierto sentido, elementos inherentes al funcionamiento de éstas. Con esto no se pretende presentar a los demandantes de ayudas sociales como estrategas que buscan "engañar" a los Servicios Sociales, sino dar sentido a las categorías que utilizan y a las poses tácticas que despliegan cuando tratan de dotarse de reconocimiento frente a éstos y ganar, a la par, el beneplácito de los trabajadores sociales.

El marco de aplicación de la RMI dibuja, de este modo, una atmósfera poco propicia para promover procesos de cambio personal y social empoderadores. Esto se debe sobre todo a que la intervención social que se realiza — para atajar problemas de vulnerabilidad social que, en muchos casos, son resultado de condiciones de índole estructural - tiene un carácter eminentemente individual y, por consiguiente, no favorece el desarrollo de "comunidades de pensamiento" ni por parte de los gitanos solicitantes/beneficiarios de RMI, ni por la de los profesionales con capacidad para decidir sobre los distintos aspectos concernientes a esta política social. Ello se ve acrecentado por ciertas tácticas desplegadas por los solicitantes/beneficiarios de menor posición social, como la que consiste, por ejemplo, en adoptar un discurso auto-inferiorizante con el objeto de eludir la moralización que suele acompañar a la conminación de los profesionales a que "hagan algo" para "salir" de su situación de exclusión social; discurso que, a su vez, acaba por generar en los trabajadores sociales una actitud de desconfianza respecto a su veracidad. Los aspectos descritos alimentan un círculo vicioso que nutre la desconfianza mutua y que necesitará de nuevos enfoques para poder ser superado.

\section{Referencias bibliográficas}

AGUILAR, Manuel; GAVIRIA, Mario; LAPARRA, Miguel Ángel

1993 El Programa Ingreso Madrileño de Integración (IMI). Primera evaluación. Consejería de Integración Social, Comunidad de Madrid.

1995 La caña y el pez. Estudio sobre los salarios sociales en las comunidades autónomas 1989-1994. Madrid: Fundación FOESSA. 
AYALA RUBIO, Ariadna.; PÉREZ-SUTIL, Rocío

2007 "La investigación cualitativa como instrumento de intervención socio-sanitaria: las lógicas de prevención de la salud de la población gitana”, actas del Congreso Anthropos 2007: I Congreso Iberoamericano de Antropología. La Habana (Cuba).

AYALA RUBIO, Ariadna; JOCILES, María Isabel; PÉREZ-SUTIL, Rocío; VILLAAMIL, Fernando

2008 Actitudes y pautas de comportamiento con relación a la salud de la población gitana madrileña. Servicio Madrileño de Salud, Subdirección de Promoción de la Salud y Prevención, Comunidad de Madrid.

AYALA RUBIO, Ariadna

2009 "Secretos a voces: exclusión social y estrategias profesionales de construcción de la obligatoriedad en la intervención social vinculada a la Renta Mínima de Inserción (RMI) con el colectivo de etnia gitana", Cuadernos de trabajo social, 22: 19-40.

AYALA RUBIO, Ariadna; GARCÍA GARCÍA, Sergio

2009a "El grado de satisfacción con las figuras profesionales de la intervención social por parte de las familias usuarias de los Servicios Sociales de Puente de Vallecas", demandado por la Empresa de Educadores Sociales (Informe no publicado).

2009b "Gestión de cuerpos y actuación de resistencias en una política social. La aplicación de la Renta Mínima de Inserción de la Comunidad de Madrid”. Revista de Antropología Experimental, 9(2): 17-36. Universidad de Jaén.

CARDOSO DE OLIVEIRA, Roberto

1993 "Etnicidad y las posibilidades de la ética planetaria". Antropológicas, 8: 20-33.

CASTEL, Robert

1996 Les métamorphoses de la question sociale. Une chronique du salariat. París: Fayard.

2004 “Encuadre de la exclusión”, en S. Karsz, La exclusión: bordeando sus fronteras. Definiciones y matices. Barcelona: Gedisa.

2006 "Crítica social. Radicalismo o reformismo político". Pensar y resistir. La sociología crítica después de Foucault. Madrid: Círculo de Bellas Artes.

COMUNIDAD AUTÓNOMA DE MADRID

2001 LEY 15/2001, de 27 de Diciembre de 2001, de Renta Mínima en el Decreto 147/2002, de 1 de Agosto de 2002, por el que se aprueba el Reglamento de la Renta Mínima de Inserción de la CAM (BOCM de 14 de Agosto de 2002).

\section{CONSEJERIA DE FAMILIA Y ASUNTOS SOCIALES}

2005 "Los programas individuales de inserción: marcoconceptual y normativo. Textos para estudio y debate", Servicio de Prevención de la Exclusión y Prevención de Rentas Mínimas de la Comunidad de Madrid.

\section{CONSEJERIA DE SANIDAD Y CONSUMO}

2005 Acceso a los servicios sanitarios de la población en los asentamientos marginales en la Comunidad de Madrid. Cañaveral, Mimbreras, Salobral, Plata y Castañar, Santa Catalina, Vereda del Pan y Agua, Quinta, Pitis y Barranquillas. Comunidad de Madrid, Dirección General de Salud Pública y Alimentación. Elaborado por EDIS. 
DE CERTEAU, Michel

1996 La invención de lo cotidiano. I. Artes de hacer. México: Universidad Iberoamericana.

DEJOURS, Christophe

1998 Souffrance en France. La banalisation de l'injustice social. París: Le Seuil.

DUBET, François., VÉRETOUT Antoine

2001 "Une réduction de la rationalité de l'acteur. Pourquoi sortir du RMI ?", Revue Française de Sociologie, 42(3): 407-436.

FASSIN, Didier

2000a "Le supplique. Stratégies rhétoriques et constructions identitaires dans les demandes d'aide d'urgence". Annales, Histoire, Science Sociales, 55(5): 955-981.

2000 b "Entre politiques du vivant et politiques de la vie. Pour une anthropologie de la santé". Anthropologie et Sociétés, 24(1): 95-116.

2001 "The biopolitics of otherness: Undocumented foreigners and racial discrimination in French public debate". Anthropology Today, 17(1).

2003 "Gobernar por los cuerpos, políticas de reconocimiento hacia los pobres ylos inmigrantes en Francia”. Cuadernos de Antropología Social, 17: 51-80.

2004 «Le corps exposé. Essai d'économie morale de l'illégitimité», en Fassin, Didier; Memmi, Dominique (eds.), Le gouvernement des corps. París: Editions de L'Ecole des Hautes Ėtudes en Sciences Sociales.

JOCILES, María Isabel

2011 "Resistiéndose ante el conocimiento experto: monoparentalidad adoptiva y tácticas para legitimar la solidaridad como motivación para adoptar", XII Congreso de Antropología de la FAAEE.

MESSU, Michel

1991 Les assistés sociaux. Analyse identitaire de un groupe social. París: Privat.

SAN ROMÁN, Teresa

2010 La diferencia inquietante: viejas y nuevas estrategias culturales de los gitanos. Madrid: Siglo XXI. Posdata, pp.275-281.

SAYAD, Abdelmalek

2004 The Suffering of the Immigrant. Cambridge, UK: Polity Press.

SERRANO, Araceli.; ARRIBA, Ana

1998 ¿Pobres o excluidos? El Ingreso Madrileño en perspectiva comparada. Madrid: Fundación Argentaria.

ZAMANILLO, Teresa (dir.)

2011 Ética, teoría y técnica. La responsabilidad política del trabajo social. Madrid: Talasa. 